\title{
An Overview of Advances in Understanding Electrostatic Charge Buildup in Gas-Solid Fluidized Beds
}

\author{
${ }^{\text {a }}$ Poupak Mehrani, ${ }^{\mathrm{b}}$ Matti Murtomaa, ${ }^{\mathrm{c}}$ Daniel J. Lacks \\ ${ }^{a}$ Department of Chemical and Biological Engineering, University of Ottawa, 161 Louis \\ Pasteur Ottawa, ON K1N 6N5, Canada \\ poupak.mehrani@uottawa.ca,Tel: 1 (613) 562-5800 Ext.6098 \\ ${ }^{b}$ Department of Physics and Astronomy, University of Turku, Turku, FIN-20014, Finland \\ matti.murtomaa@utu.fi,Tel.: +358-2-3335735 \\ ${ }^{c}$ Department of Chemical and Biomolecular Engineering, Case Western Reserve University \\ Cleveland, OH 44106, USA \\ daniel.lacks@case.edu,Tel:1(216)368-4238
}

\begin{abstract}
Electrostatic charging of particles in gas-solid fluidized beds often results in operational complications in commercial processes. This paper provides a comprehensive review of the advances from the last decade in three key areas, namely the fundamental understanding of triboelectric charging, methods to measure particle charge, and experiments to elucidate particle charging processes in fluidized beds. This review underscores the need for better understanding the mechanisms of triboelectric charging in granular systems, effective online charge monitoring techniques, and experiments under industrially relevant conditions to better comprehend the problems in commercial reactors that can enable strategies to mitigate charging.
\end{abstract}

Keywords: Triboelectrification; Gas-Solid Fluidized Bed; Charge Measurement Methods; Charging Mechanisms; 


\section{Introduction}

Gas-solid fluidization technology is widely employed in many industries such as oil and gas, mining, chemical, food and agriculture, etc., for various applications including catalytic reactions, drying, mixing, just to name a few. The widespread usage of the technology is due to its high heat and mass transfer capability. Such characteristics are provided by the high levels of contact between the fluidizing gas and solids which also result in frequent collisions between the fluidizing particles as well as the particles and the fluidization column wall. A major nuisance resulting from such continuous particle contacts is the generation of electrostatic charge. The generated charges might cause particle agglomeration causing deviation from the desired bed hydrodynamic behavior, electrostatic discharge endangering operators and equipment, and the adhesion of particles to the fluidization column wall and other surfaces necessitating regular shutdown for clean-up. The extent of charging would vary from one system to another depending on the physical and chemical properties of the surfaces in contact (i.e., fluidizing particles and fluidization column wall) as well as the hydrodynamic conditions of the fluidized bed.

One industry which has faced operational challenges due to the generation of electrostatic charges is the polyolefin industry. For example, in the catalytic polymerization of ethylene to produce polyethylene, the accumulation of electrostatic charges in the fluidized bed reactor is a major nuisance primarily due to occurrence of a problem known as "sheeting". In such reactors the charge buildup on the fluidizing polyethylene and catalyst particles results in their adhesion to the reactor wall where the heat of exothermic polymerization reaction may not be removed as much and thus resulting in the particles to melt and form sheets along the reactor wall. Industrially, a reactor might operate for only a few hours before sheeting necessitates its shutdown for clean-up [1]. Hendrickson provided a comprehensive review of polymer reactor electrification resulting in sheeting, as well as the academic works reported in the literature pertaining to understanding of the fluid bed electrification [2]. Hendrickson concluded that further research was still necessary in relation to wall sheeting formation in polymer reactors as well as its detection since it was shown that most of the research reported was carried out at conditions that were not typical of commercial polymerization reactors. They included, the usage of humid air, usage of particles that had properties far from polymers such as polyethylene and usage of small scale equipment.

The existence of electrostatic charges in gas-solid fluidized beds have been reported for many decades [3] and there have been studies attempting to study this phenomenon for almost as long [4]. But although there has been some progress in the understanding of electrostatic charging in fluidized beds and a number of proposed solutions, the problem still persists. This is partly due to complex nature of the fluidization process as well as the complex nature of the electrostatic phenomenon. Thus there is still a great need to better understand the fundamental mechanisms of charge generation and dissipation in gas-solid fluidized beds. Over the past ten years much research has been carried in an attempt to advance the understanding of electrostatic charging in fluid beds. The specific areas of research include: 
advances in charge measurement techniques applied in gas phase fluid beds; mechanisms of surface charging including better understanding of triboelectrification in insulators; and describing the effects of bed hydrodynamics and operating conditions on electrostatic charge generation and distribution within a fluidized bed. This paper reviews the advances made over the years from the fundamental understanding of triboelectrification to measurement methods developed to better quantify the degree of charging, and experimental works carried out to better understand fluid bed electrification.

\section{Triboelectrification}

When two neutral surfaces are brought into contact and then separated, transfer of charge generally occurs such that one surface becomes charged positively and the other surface becomes charged negatively if at least one of the materials is insulating. This phenomenon, which is called "triboelectric charging" or "contact electrification", has been written about since antiquity. It is a surprise to most people that our scientific understanding of triboelectric charging has not progressed significantly over this time. Triboelectric charging is a very complex and difficult-to-study process, both theoretically and experimentally. We briefly describe below what we feel are the most important open questions in the area, why the answers to these questions are difficult, and the state of current understanding.

\subsection{The charge carriers}

It is not known what species act as charge carriers in the charging process - the species could be electrons, ions, or pieces of material. The identity of the charge carriers is difficult to determine because the charge carriers represent a very small fraction of surface atoms. A typical value of the surface charge density on a highly charged surface is $10^{-5} \mathrm{C} / \mathrm{m}^{2}$. As one elementary charge is $1.6 \times 10^{-19} \mathrm{C}$ and there are $10^{+18} \mathrm{~nm}^{2}$ per $\mathrm{m}^{2}$, this charge density corresponds to or $10^{-4}$ elementary charges per $\mathrm{nm}^{2}$. Since the diameter of an atom is approximately $0.3 \mathrm{~nm}$, there are approximately 10 surface atoms per $\mathrm{nm}^{2}$. Thus, on a highly charged surface there is only about one excess elementary charge per approximately 100,000 surface atoms. Such a small concentration is very difficult to detect experimentally or to analyze with theoretical models.

Electron transfer - On first glance there seems to be no mechanism for electron transfer between surfaces of insulator materials. In the standard picture of electrical insulators, the valence bands are filled and there is a very large energy gap between the valence band and the conduction band. Such a large energy gap would make it unlikely for an electron to transfer from a valence state on one surface to a conduction state on the other surface (transfer to a valence state on the other surface would not be possible as these states are filled). However, in real materials the gap between the valence and conduction bands is not really empty of states; rather, there are states with intermediate energies due to the presence of surfaces and conformational and chemical defects. These gap-states, which lead to the finite conductivity of "insulators", could also provide a means for triboelectric charging to occur. Many studies have suggested the role of electrons in triboelectric charging (see review

articles by Lowell and Rose-Innes [5] and by Lacks and Sankaran [6]). 
Ion transfer - In certain situations it is clear that the transfer of ions underlies triboelectric charging. Materials can be synthesized with loosely-bound ions at the surfaces, and for these materials the triboelectric charging results are consistent with the transfer of these looselybound ions [7-9]. Furthermore, experiments have shown that in some materials without these loosely-bound ions, there have been observations that point towards adsorbed ions being the charge carrier rather than electrons, these observations include changes in electrostatic charge in response to changes in pressure [10,11] and relative humidity [12,13], presumably because the changes in pressure and humidity alter the thermodynamics of ion adsorption on the surface. In these cases, the ions likely come from the environment, and reside in surface water layers due to ambient humidity.

Material transfer - When two surfaces are contacted, 'patches' of material generally transfer from one surface to another. X-ray photoelectron spectroscopy provides direct evidence of transferred material $[14,15]$. The patch of material may be charged, and thus provide a means for charge transfer. For this mechanism, there is certainly clear experimental evidence that material is transferred; however, there is no clear evidence that this transferred material is the origin of the charging.

\subsection{Direction of charge transfer}

It cannot be generally predicted which surface will charge positively and which will charge negatively. Theoretical efforts to answer this are thwarted by not knowing the identity of the charge transfer species. Experiments on triboelectric charging are difficult because: (a) they can be affected by any contact with external surfaces, due to charge transfer between the sample and the surface; and (b) small trace impurities could potentially dominate charging results, since as discussed above charge carriers are in concentrations of about 1 in $10^{5}$ surface atoms.

First, we point out that even the idea of there being a positively charged surface and a negatively charged surface is a simplification. Rather, surfaces have regions of both positive charge and negative charge $[15,16]$. Thus when we refer to a macroscopic surface as "positive" or "negative" it is referring to the net charge, with the understanding that the surface likely has a distribution of charges encompassing both polarities.

The most obvious factor affecting the direction of charge transfer is the chemical composition of the two surfaces. We would expect that materials will differ in their propensity to donate or accept positive or negative charge based on the types of atoms and bonds in the materials. In charge transfer for some materials, such as between two metal surfaces or involving materials synthesized with loosely-bound ions, it is possible to determine the direction of charge transfer [7-9]. However, in most cases the direction of charge transfer cannot be rationally related to the chemical composition. The limited success may be due to different mechanisms of charge transfer occurring for different materials.

Empirical methods, with no rational basis, have long been used to attempt to relate the direction of charge transfer to the chemical composition of the material. The triboelectric series is an empirical ordered list of materials such that when a material higher on the list 
contacts a material lower on the list, the material higher on the list charges positively and the material lower on the list charges negatively. While the triboelectric series approach often works, there are often cases where it does not - for example, different researchers often find different orderings for the triboelectric series [17]. A more fundamental problem with the triboelectric series is that triboelectric charging occurs even when the two surfaces that are contacted have the same chemical composition - according a triboelectric series approach there should be no triboelectric charging in this situation.

A further complication is that there is a long history of evidence that suggests stress affects electrostatic charging [18]. Triboelectric charging appears to be affected by surface damage, and these effects are reversed by annealing $[19,20]$. Sow et al. have shown that changes in the strain state of a material could reverse the direction of charge transfer when that material contacts another material [21,22]. Contact in asymmetric geometries also leads to strain differences in the surfaces that appear to provide a driving force for charge transfer [23].

\subsection{Magnitude of charge transfer}

Triboelectric charging is a non-equilibrium process - the equilibrium state of two separated surfaces is neutral rather than charged. As two neutral surfaces are brought into contact, the equilibrium state of the system generally corresponds to charged surfaces. If the surfaces move apart while maintaining equilibrium, "charge backflow" will occur to return to the system to two neutral surfaces. However, the kinetics of the charge backflow (i.e., the rate at which the process occurs), slows down exponentially as the surfaces separate, as the charge has to "jump" across the gap between the surfaces; physically, the gap creates an energy barrier to the backflow process, and the energy barrier becomes increasingly large as the gap increases. For gap distances greater than approximately $1 \mathrm{~nm}$, the rate of the charge transfer process is effectively zero [5]. Thus, in practice, as the surfaces that were in contact are subsequently separated, residual charge remains on the surfaces after they are fully separated due to the kinetics. This residual charge is what we observe as triboelectric charging.

In regard to the magnitude of charge that remains on the surfaces after they are separated, there are three factors that will likely control this. First, the electric fields that build up as charge is transferred will limit further charge transfer [24]; for example, if negative charge is transferred from surface A to surface B, the charge separation leads to an electric field that make it unfavorable to transfer more negative charge in this direction. Second, as charged surfaces move apart, electrical discharges due to breakdown of air can limit the magnitude of charge on surfaces [25]. Third, charge leakage to ground can occur; this effect is enhanced by high humidity, which acts to increase the surface conductivity.

\subsection{Granular materials}

The charging behavior of granular materials can be considered in two regimes. In a lowdensity regime, for example in the case of entrained particles in a gas stream, the charging behavior will be dominated by interactions of particles with the containing walls. The charging behavior in this regime has been is described by Matsusaka et al. [26]. 
In the high-density regime, which is the case for fluidized beds, the interaction of particles with other particles will be significant and in many cases dominating the charging behavior (depending on the diameter of the column). In this case bipolar charging can occur, and the distribution or charge is much more important in many situations than the net charge of the collection of particles. For example, the net charge of the material may be zero, but with half of the particles being very highly positively charged and the other half of the particles being very highly negatively charged. In multicomponent mixtures, the presence of positively and negatively charged particles would be expected due to the different chemical compositions of the particles. However, similar bipolar charging occurs for particles of a single material composition (see review article by Lacks and Sankaran [27]).

A curious phenomenon in granular systems composed of a single chemical composition is that there is a tendency for larger particles to charge to one polarity and smaller particles to charge to the opposite polarity. This effect was first noticed in dust storms, in which studies found dipolar electric fields oriented perpendicular to the earth's surface with the negative pole at the higher elevation [28-32]. This observation was interpreted as follows: (1) the smaller particles charge negatively and the larger particles charge positively due to particleparticle collisions; (2) the smaller particles are lighter they get lofted by the wind to higher elevations than the larger particles. These two factors would combine to give the observed dipolar electric field. Similar electrical fields have been found in dusts of polymer particles $[33,34]$ and in volcanic plumes [35]. We note that in some studies the opposite electrical field polarity has been observed [36]. Experiments to directly measure the particle-sizedependence of particle have been carried out on a range of materials, and have found, in most cases, that the smaller particles tend to charge negatively while the larger particles tend to charge positively [37-47]. A few experiments have found the opposite polarity [48].

The particle-size dependent polarity of charging leads to important consequences. For example, the particles cluster into 'molecule-like' arrangements due to the correlation of size and charge [47]. Also, the magnitude of electrostatic charging becomes greater when the particle size distribution is broader, presumably for the same reasons that lead to charging $[49,50]$.

The origin of this effect is not obvious. Since the particles of interest are macroscopic and $>10 \mu \mathrm{m}$, the effect will not be due to a particle-size-dependence of material properties. Lacks and co-workers have presented a theory for this effect [51,52] based on the non-equilibrium dynamics of a charged species after many particle-particle collisions. In initial versions of the theory, it was assumed these species were electrons, but Castle [53] pointed out that the theory is valid for ions as well. Recently, Waitukaitis et al. [46] carried out experiments to test the validity of this theory on the basis of electrons, and showed that the density of nonequilibrium electrons is too low for the version of the theory based on electrons to be valid (but the theory could still be valid based on ions). An alternative theory was put forth by Xie et al. [54], based on experiments that show that a particle-size-based asymmetry of charging occurs in single collisions between different sized particles composed of the same material (the particle sizes were relatively large $\sim 1 \mathrm{~cm}$ ). Based on these results, Xie et al. argue that strain asymmetries occurring during contact of different sized particles provide the driving 
force for charge transfer. A third theory was put forth by Pähtz et al. [55], who show that particle collisions in the presence of an electric field will lead to a systematic transfer of charge in one direction, when the electrical field aligns with the gravitational field.

\subsection{Summary and outlook}

As described above, the scientific understanding of triboelectric charging is very poor. For example, it is not known whether the transfer of electrons, ions or bits of material are responsible for the charging, and the direction and magnitude of charging cannot be predicted based on material properties. The basis of this difficulty may be that a number of mechanisms could play a role in electrostatic charging, with different mechanisms dominating in different situations.

Nonetheless, we expect progress to continue towards in understanding macroscopic charging behaviors and their implications. For example, the particle-size-dependent charging in granular materials has implications in fluidized beds, in that charging behaviors may differ depending on the particle size distribution. A better understanding of this behavior requires improvements in measurement techniques, so that the particle-size effect can be better characterized. The measurement techniques are the subject of the next section.

\section{Measurement Methods}

Measurement of charge generation in fluidized beds has become increasingly important with the increased use of fluidized beds in different branches of industry, especially in pharmaceutical and polyolefin production. While sampling techniques can readily be applied to carry out measurements in a laboratory, online methods are preferential for large scale operations. Online measurement of particle charge density would allow plant operators to take preventive actions before electrostatically charged particles cause problems. Additionally, since fluidized beds have proven to be a powerful method for powder charging in fundamental electrostatics research due the well-defined and reproducible particle charging, accurate monitoring of charge generation would enable researchers to perform studies under controlled atmospheres, process parameters and materials/additives. Such studies could lead to a better understanding of the theory of electrostatic charging; as described above this understanding is currently very weak.

\subsection{Measuring bed potential with a hanging ball probe}

The first electrostatic measurements in fluidized beds were performed in 1960s using a metal probe immersed in the fluidized bed. Ciborowski and Wlodarski hung a small metal ball with a thin platinum wire connected to an electrometer [4]. Thus, the probe was parallel to the axis of the fluidized bed column. They also tried to use a perpendicular probe introduced through an opening in the walls but these experiments proved to be difficult due to current leakage at higher potentials. This perpendicular arrangement has now become common in commercial instruments. The probe potential was measured using an electrometer. The main observations in their work were that: (a) the probe potential increased with fluidizing air velocity for beds of vinyl polyacetate, polystyrol and sand particles fluidized in a glass column; (b) the probe 
potential varied with humidity; (c) the highest particle adhesion on the column walls was found to correlate with the highest probe potential.

In 1967, Kisel'nikov et. al. used a similar apparatus and observed that the probe potential increased with increasing height of the probe above the grounded distributor plate, reached a maximum near the height of fixed bed, and reduced in magnitude when the height was further increased [56]. The change in the probe potential with time was quickest at the beginning of fluidization, and the potential reached steady-state after about 5 to 20 minutes (depending on the materials used). Bafrnec and Beňa used a hanging ball probe to study charging of glass beads in a metal column [57]. They assumed that a particle acquires a charge when it contacted the column wall, and that the particle successively delivered its charge to the probe if the potential of the particle and the probe were different. Thus, the potential of the probe would become the same as of particles. In their experiment in 1972, Bafrnec and Beňa showed that the charge from a charged powder is directly transferred to the metal probe [57], and thus the polarity of the probe is the same as of the powder.

Rojo et. al. [58] used a probe that was a rod parallel to the column axis instead of a hanging ball. They studied the charging of mixtures of dielectric/conducting particles during fluidization [59] as well as the influence of particle size, fluidization velocity and relative humidity [60]. Adhesion of charged particles on the probe at low humidity was found to cause poor reproducibility of potential measurements.

The assessment of powder charge using the above mentioned systems is problematic, as shown by Fujino et. al. [61]. While the potential is directly proportional to the charge on the probe, the spatial position of this charge is not well defined, as the "probe" is either an extended rod or the combination of the metal ball and the wire attached to the ball. Furthermore, the charge on the probe consists of both the induced charge caused by the electric field generated by charged powder and the charge transferred between the probe and the powder, and differentiating between these two factors can be quite problematic. Additionally, the probe potential is inversely proportional to the capacitance of the probe with respect to ground, which complicates the analysis because the capacitance depends on geometric factors including the size and location of the probe, signal wires, the dimensions and materials of the column, etc. Fujino et. al. also tried to correlate measured probe potentials with the charge of the powder. They used Poisson's and Laplace's equations to calculate the bed potential. For calculations, they used specific charge (charge-to-mass ratio) obtained using a Faraday pail. In the theoretical model, the column wall was either grounded (metal column) or insulating. Their study showed that the highest electric field located at the wall of the metal column. There were differences between calculated potentials and ball probe potentials, which can be attributed to the fact that the ball probe was not included in the calculations.

Due to these uncertainties, charge measurement using this kind of hanging potential probe has been largely discontinued. However, more sophisticated ball probes together with more complex theoretical analyses are still used. 


\subsection{Induction probes}

When fluidized particles contact a probe, charge exchange takes place between the two surfaces; the polarity and magnitude of the transferred charge depends on the probe material, which can be different than the column material. Therefore, a simple current or potential measurement in such case does not provide much information about the charge of the fluidized powder. For example, if the fluidized powder is electrically neutral and does not charge in contact with the fluidization column but charging takes place between the powder and the probe, cumulative measurement of current could imply significant charging. Closer examination of the probe signal (either current or potential) reveals that it arises from both contact charging and from the charge density variations in the vicinity of the probe. In bubbling fluidized beds, these charge density variations are caused by rising gas bubbles. As a simple model, moving bubbles within a charged powder are similar to charged spheres moving in air. For example, for an uniformly negatively charged bed of a powder, a positive charge will be induced on the probe. As a gas bubble approaches the probe, charge density near the probe decreases and part of this induced charge on the probe will flow to current meter and a positive current signal is recorded. The signal would be similar if a positively charged sphere travelling in air approached the same probe. When a gas bubble (or a charged sphere) is closest to the probe, current signal goes to zero and turns negative as the bubble (or sphere) moves away (Fig. 1). Eventually, the current signal will approach zero. The integrated areas of the positive and negative current peaks as a function of time give the amount of induced charge on the probe. If charge exchange between the powder and the probe takes place, the areas differ by the amount of transferred charge.

If the probe is set to potential mode where the input impedance is "infinite", a unipolar curve similar to integrated current signal is obtained. Indeed, the amplitude of that curve is directly proportional to the induced charge and the proportional factor is the inverse of the probe capacitance. The height of the baseline depends on the charge already on the probe and circuitry. If no charge exchange takes place (i.e. the signal is purely inductive), the signal will return to the same baseline after the gas bubble has passed. If charge exchange does take place, the potential difference before and after the passage gives the amount of transferred charge when multiplied with the capacitance.
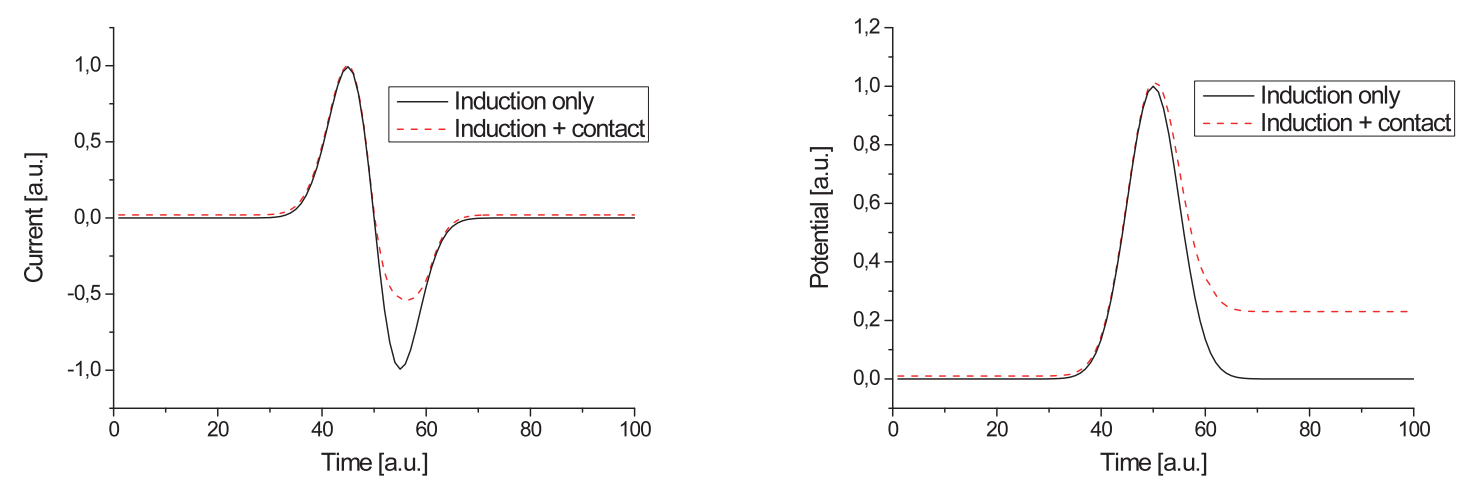
Figure 1. Schematic current (left) and potential (right) signals without (black) and with (red) contact charging.

Boland and Geldart studied both potential and current signals using an induction probe which was separated from the two dimensional fluidized bed with a thin layer Perspex [62]. The probe was placed perpendicular to the face of the $2 \mathrm{D}$ column. They reported the signal shapes for passing bubbles but did not relate the signals to any value of charge in coulombs. They did, however, measure the peak areas of current signals and used those to compare the charge as a function of particle size. They also applied similar induction probe to a $3 \mathrm{D}$ fluidized bed. This time the probe was located vertically on the axis of the column. Current signals were recorded from injected bubbles but no further analysis was performed.

Others have studied the signals induced on a spherical probe with gas bubble passage [6366]. In their model, the charge density is zero inside the bubble, has a maximum value at the bubble surface, and the charge density decays exponentially to a steady-state value far from the bubble (i.e. background charge density). The induced charge on the probe was calculated using the method of images. Transferred charge due to collisions was calculated according to method presented by Zhu and Soo [67]. Authors also considered bubbles which were not spherical but "kidney-shaped" and different charge densities at the bubble drift region. Relatively good agreement with simulated and experimental data from a 2D fluidized bed was reported.

Chen et al. introduced a horizontal array of 4 to 8 induction probes at a $2 \mathrm{D}$ fluidized bed $[68,69]$ for measurement of charge distribution around gas bubbles. Their results seem to suggest that the charge distribution surrounding injected bubbles is symmetrical but in a freely bubbling bed the charge density is higher at the bubble wake.

General problem which limits the usability of many of the methods presented above is the fact that the results only apply to 2D fluidized beds where the bubble of predetermined size passes the probe. In real systems, gas bubbles of variable size pass the probe at arbitrary distances.

Murtomaa et. al. measured the charge of lactose monohydrate, microcrystalline cellulose and glass beads fluidized in a glass and acrylic columns [70]. Their method consisted of a ring shaped induction probe placed around the fluidized bed which scanned the bed vertically and the potential as a function of probe height was recorded. The system was mathematically modeled but the most reliable results were obtained by simulating the recorded signals using a finite element method. This method can be used with small columns made of an insulating material only, and the adhesion of powder above the bed level together with time-consuming simulations limits the use of this method.

A coaxial induction probe consisting of an inner induction sensor surrounded by a circular outer sensor has been proposed by Peltonen and Murtomaa [71,72]. In their method, current signals from the sensors were recorded as a bubble (or a charged sphere) passed the probe in a 3D fluidized bed. The shapes of the signals were analyzed and compared with computer simulations. From the shape parameters, bubble size, distance from the probe and charge 
were calculated. The probe was further developed by splitting the outer sensor in two (Fig. 2.) [73]. Then, bubbles which passed the probe asymmetrically could also be analyzed. At the present, this method suffers from the fact that either bubble velocity or distance needs to be fixed in order to be able to precisely calculate the other parameters.

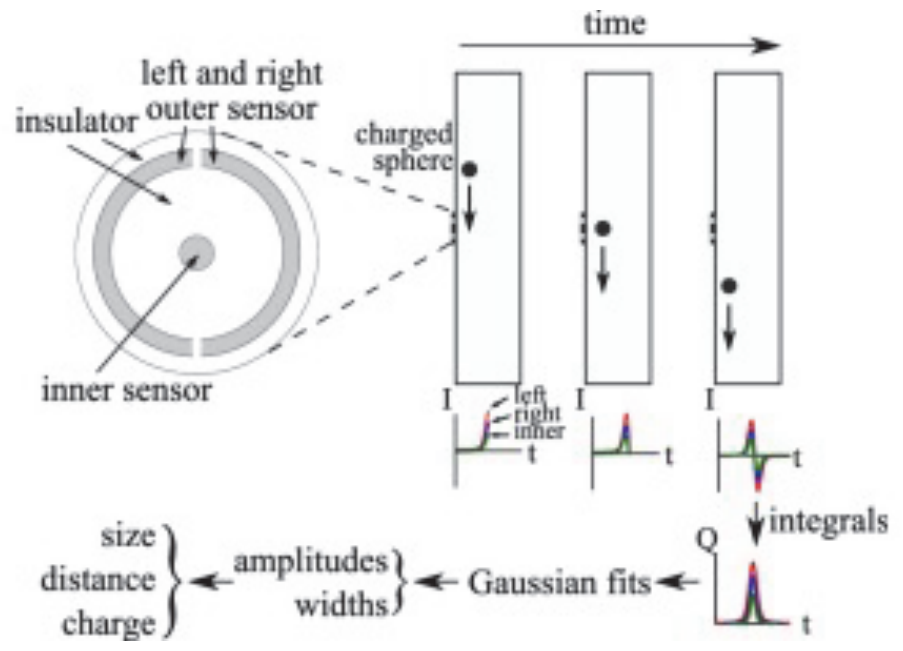

Figure 2. Schematic image and the working principle of a coaxial induction probe [73].

\subsection{Collision probes; measurement of cumulative charge, potential or current}

Impacts between the probe and the fluidized powder result in charge transfer between the two. If induction signals are neglected, i.e. the sampling rate is low or mean values are used, a cumulative signal is obtained. If the probe is operated in current mode, the integrated current with time gives the charge transferred to the probe. If the probe is operating in voltage mode, the potential is related to the charge and the capacitance of the probe.

Gajewski used six copper rings glued on the inner surface of a glass column and measured current signals from different heights of the bed [74]. The distributor plate also served as an electrode. The fluidized material consisted of polypropylene particles. He concluded that charging mainly took place at the distributor plate while charge dissipated mainly above the static bed level. Basically similar system was applied by Zhang et. al. but they also added a pressure measurement over the rings [75]. A frequency analysis of both current and pressure signals was performed and a strong correlation between the two was observed. Thus, it was shown that induced current on the electrodes originates from the changes in charge density, i.e. passing bubbles. Quite similar method was also applied by Tiyapiboonchaiya et. al. who measured instantaneous current recorded from five copper strips at the inner surface of an acrylic column [76].

McMillan, et. al. placed 28 parallel insulated copper wires horizontally in a fluidized bed of silica sand particles [77]. A $5 \mathrm{~mm}$ long area of each copper wire was stripped from the insulator. As fluidized particles contacted the exposed copper, current signals were generated and recorded. From the 28 signals, mean, absolute deviation, standard deviation, coefficient of variation, skewness and kurtosis was analyzed. The authors came up with an empirical 
formula which related the particle diameter to the electrostatic signal. Also, authors suggested that this method could be used to measure the proportion of fines within the fluidized bed.

Wang et. al. studied the potential distribution inside a fluidized bed by placing potential probes at different locations [78-80]. They reported steady-state bed potentials by fitting an exponential curve to the measured potential as a function of fluidization time. Similar to Gajewski [74], they noticed a change of polarity at the bed level. Use of different liquid and solid static agents had a great effect on the magnitude and polarity of recorded potentials.

Triboelectric current generated between glass or sand particles and stainless steel probes has been related to solid moisture content of a fluidized bed by Portoghese et. al. [81,82]. Several probes were placed horizontally inside a fluidized bed. The probes were covered with Teflon sleeve except the $2-3 \mathrm{~mm}$ long tip of the probe. The current was shown to increase as water was injected into the bed and decrease as powder dried.

Brennan et. al. placed three triboelectric probes vertically in a vibrated fluidized bed and measured resulting current signals [83]. Probes were located at different radial distances from the axis and different heights. They were made of stainless steel covered with an insulating polymer except the $10 \mathrm{~mm}$ long tip. The probes were used to detect minimum bubbling velocity and drying of the powder with and without additional vibration.

Measurement of cumulative charge has been used to study the effect of pressure, temperature and gas velocity on the charging of glass beads and polyethylene resins in a stainless steel column [84-86]. It was reported that charge measured by the collision probe increased with increasing pressure and superficial gas velocity.

A measurement system developed by Muhle, et. al. can also be considered as a collision probe. In their system, the holes in the air distributor were covered with metallic caps isolated from the air distributor but connected to a monitoring device such as an electrometer or a picoammeter [87]. As particles hit the caps, charging takes place and a signal can be recorded. As with all probes immersed in fluidized beds, charging signals and induction signals caused by changes in the local charge density can be difficult to differentiate.

\subsection{Sampling methods}

With most of the aforementioned measurement methods, charge of the fluidized powder has been reported using recorded potential of the probe, current or cumulative charge collected on the probe. Thus, they do not provide the actual powder charge-to-mass ratio $\left(\mathrm{Ckg}^{-1}\right)$ or charge density $\left(\mathrm{Cm}^{-3}\right)$ but are more or less measures of charge transfer between the powder and the probe. Signals may depend on fluid bed hydrodynamics and on the capacitance of the system, for example. However, taking a sample from the fluidized powder and measuring its charge using a Faraday pail is a reliable method for determining the powder charge in coulombs. A Faraday pail typically consists of two metallic "cups" of which outer one is grounded and the inner one is connected to a high input impedance voltmeter (e.g. electrometer). The cups are electrically insulated from each other and as a charged object is placed inside the pail, its charge can be directly measured. But Faraday pail measurements have some disadvantages. Firstly, taking a sample from the fluidized bed might cause some additional charge due to 
particle handling. Secondly, only the net charge of the sample can be measured. Thirdly, sampling methods are sometimes difficult to apply in industrial processes, especially if a continuous on-line operation is required.

Wolny and Opalinski used a vacuum sampling tube to remove individual polystyrene beads from the bed and to transfer them into a Faraday pail [88]. It is possible that measured charges were affected through sampling, especially because all studied beads were contacted with the sampling tube. Generally in Faraday pail measurements, sampling related errors can be minimized by using as large of a sample as possible and by minimizing the contact area between the powder and the sampler. Also, since same materials do not usually exchange much charge when in contact with each other, the sampling unit (e.g. scooper, spoon) can be coated with the same material of the fluidized powder. Ali et. al. used this technique when they measured the charge of polyamide powder fluidized in a steel column [89].

Since particles segregate according to their size in fluidized beds, sampling can be performed at different heights of the bed [90,91]. It is advised to use as short sampling tubes as possible to prevent additional charging especially if the tube is inclined. Vertical sampling tube located axially inside fluidized bed device has been used by Tardos and Pfeffer [92]. When a lock on top of the sampling tube was opened, granules fell directly into a Faraday pail located below the device.

Jalalinejad et. al. designed a Faraday pail which was mounted on the face of a 2D-column and which allowed particles to enter the pail without additional contacts [93,94]. It is also possible to design a sampling tube which acts as an integral part of the Faraday pail. Fasso et. al. used a suction pipe made of two concentric pipes insulated from each other and connected to corresponding cups in a Faraday pail [95]. The pail was equipped with a millipore filter for collecting the particles. Alsmari developed quite a similar system with a conical suction section located above the fluidized bed to measure the charge of fine particles in the freeboard region $[86,96]$.

Sowinski et. al. developed a method in which the distributor plate could be removed by using a modified pneumatic knife gate valve as the distributor plate. After removing the distributor plate, the charged powder fell directly into a Faraday pail located in the windbox [97]. Similar method was later used to study the effect of humidity on the charging of various powders having different resistivities [98]. Sowinski et. al. later developed their previous system [97] to collect fines. Additional Faraday pail with a filter bag was placed on top of the column to collect entrained fines and to measure their charge [48]. In addition to particles which were dropped into the Faraday pail and entrained fines, also particles adhered on the column walls were studied by removing them by tapping the column. Released particles were collected into a Faraday pail for charge measurement $[99,100]$. The above mentioned system has also been used at elevated pressures up to 25 barg [101]. 

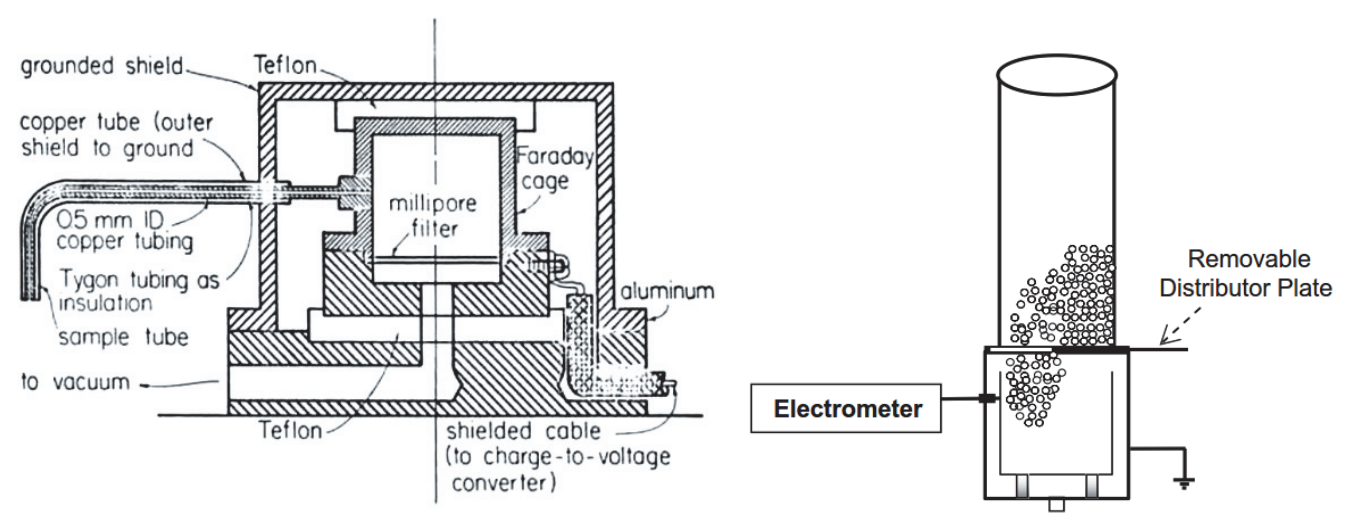

Figure 3. On the left: Two concentric sampling pipes act as an integral part of a Faraday pail [95]. On the right: Charged powder drops directly into a Faraday pail when the air distributor plate is quickly removed [97].

When a single component powder is fluidized in a column, particles acquire dominantly unipolar charge in contact with the wall based on triboelectric series. In particle-particle contacts, however, bipolar charging occurs. Salama et al. measured bipolar charge of bulk powder and adhered particles by placing an electrostatic separator under the fluidized bed used by Sowinski et al. [102]. When the distributor plate was removed, charged particles fell directly into the electrostatic separator. A high voltage was applied to inclined plates which generated an electric field causing the positive and negative particles to be separate. Particles were then collected in four Faraday pails according to their polarity.

Albrecht et. al. also used separation in electric field to measure bipolar charging of several polymers charged in fluidized bed [103]. They concluded that the surface of a polymer particle may contain areas of positively and negatively areas. Solvatochromic measurements revealed that electron pair accepting and donating properties correlate very well with the measured charges.

Zhao et. al. studied bipolar charging of polydisperse powders charged in fluidized bed [38]. Sampling tube was places axially inside the fluidized bed. The tube had holes which allowed samples to be taken at different heights of the bed. The sampling tube was covered with the fluidized polymer in order to reduce sampling related errors. The particles were then dropped into a vertical array of 6 open ended Faraday pails and one normal Faraday pail at the bottom. In this system, larger particles fall more quickly than the small particles due to different air drag force. As the particles fall, coulombic repulsion forces expand the particle cloud, and thus particles are collected at different Faraday pails according to their size and charge.

\subsection{Other methods}

Wolny and Kaźmierczak fluidized polystyrene particles and studied the charge of individual particles [104]. After 15 minutes of fluidization, a short air pulse from a nozzle located $2-3$ $\mathrm{mm}$ below the expanded bed level was applied. The air pulse ejected some particles between two brass plates which were connected to a high voltage source. Trajectories of the ejected particles were recorded using a high speed camera and from the trajectories, charge-to-mass ratio was calculated. 
Watano et. al. developed an electric field meter which was based on a vibrating tuning fork which modulates the induced charge on a sensing electrode [105]. Their sensor was equipped with a purge air flow which allowed the sensor to be placed at the wall of a fluidized bed. The charged powder generated an electric field which was monitored during a fluidization cycle consisting of mixing, dampening and drying phases. The electric field was shown to increase during mixing, it decreased during the spraying of granulation liquid due to increased conductivity, and increased again when the powder was dried. Although the results seem convincing, this method has not been further applied in fluidized beds but in pneumatic conveying.

In laboratory scale, the column of the fluidized bed device can act as a Faraday cup. Mehrani et. al. isolated the column, shielded it from outside interference and connected it directly to an electrometer [106,107]. Faraday cup does not measure any charging taking place inside the cup, only charges taken inside or withdrawn from the cup can be measured. Thus, this system could only be used to study the charge carried by the entrained fines. It was also shown that the fluidizing gas itself is not able to carry charge.

He et. al developed a collision probe which consisted of two different materials ( $\mathrm{Ni}$ and $\mathrm{TiN}$ ) which differ considerably by their work function [108]. The probe was first used to measure the charge of a particle flow and the study was later extended to fluidized beds. As particles collide with the probes, charge is transferred. This transferred charge depends on the probe materials and the initial charge [109] but also on the particle impact velocity. The probe was calibrated with a Faraday pail and a semi-empirical set of equations was established. Later, a modified probe was used in 2D column [110]. Current peaks from both probes were carefully analyzed and reasonably good agreement between charge recorded with the probe and Faraday pail was obtained. The probe also gave information about the bubble rise velocity which was confirmed by video analysis. The tips were later made of same material (nickel) and aligned vertically to be able to measure the bubble rise velocity more precisely [111]. In their latest paper, $\mathrm{Ni}$ and $\mathrm{TiN}$ were again used as probe tips and different signal processing methods were compared [112]. It was assumed that recorded current signals (sum of transferred and induction current) were functions of specific charge of the powder and bubble rise velocity. Bubble rise velocity, on the other hand, is a function of bubble diameter [113]. In the presented method, bubble needs to collide with the probe and indeed the experimental constants were defined using either two dimensional bed with confined bubbles, or particle flow directed towards the probe tips. The distance between the bubble and the probe must have a significant effect on the recorded current signals. Still, using a strict criteria for current peak selection, the authors were able to calculate the charge density and bubble velocity with satisfactory accuracy.

\subsection{Discussion and future challenges}

Many different methods have been developed for measuring the charge of powders in fluidized beds. However, there are several issues to be resolved before a reliable method for online monitoring of charging can be applied in a large-scale commercial fluidized bed. 
Sampling techniques are not applicable to large-scale industrial processes at the moment. If sampling techniques were to be used, they should be operable at elevated pressures and temperatures for specific applications. Also, it would be advisable to be able to take samples at different locations of the fluidized bed which might turn out to be troublesome compared to other measurement methods such as induction probes. The system should be able to provide online data which requires quick automated sampling and data analysis. Conversely, a special strength of sampling methods is that, to date, sampling has been the only possible way to study bipolar charging in fluidized beds by separating oppositely charged particles in an electric field. An induction probe, for example, could imply a net neutral powder which could actually contain a fraction of highly charged small particles, which adheres on the column walls.

Collision probes, which measure cumulative charge, current or potential, suffer from the fact that charging between the probe and the particles might be different from charging between the fluidization column and the particles. Moreover, the probe surface is subjected to continuous flux of particles which changes the surface properties (and the charging) of the probe in an unpredictable manner. Collision probes need to be calibrated for specific powders and due to modification of the probe surface with time, the signal might drift uncontrollably.

Probes based on pure induction might turn out to be the most feasible for online charge measurement since the adhesion of powder to the probe or the time-dependent modification of the probe surface does not affect the signals. To date the best results have been obtained in 2D fluidized beds with confined bubble trajectories and bubble sizes. Data analysis is more difficult in freely bubbling 3D fluidized beds. It is often assumed that the bubbles are spherical, they pass the probe symmetrically, and that the bed is operating in bubbling regime. Reliable measurements especially in turbulent flow regimes remain a challenge for this kind of measurement.

\section{Evaluation of Fluid Bed Electrification}

Electrostatic charge generation and dissipation in fluidized beds is due to contacts among particles and the particles and the fluidization column wall, hence the extent of electrification is influenced by the degree of particles mixing which is affected by changes in the bed hydrodynamics. In contrast, charging of the fluidizing particles affects the interparticle forces leading to particle agglomeration and clustering, as well as particles adhesion to the fluidization column wall which in turn affects the fluid bed hydrodynamics. Therefore, fluidized bed hydrodynamics and electrostatic charging are interrelated with one affecting the other, and vice versa.

\subsection{Effect of electrostatic charging on bed hydrodynamics}

In addition to the operational challenges such as fluid bed wall sheeting, generation of electrostatic charges within a fluidized bed could potentially influence the bed hydrodynamics. Two of the important parameters to consider include gas bubble characteristics, and entrainment. 


\subsubsection{Gas bubble dynamics}

In gas-solid fluidized beds, gas bubbles are formed at the distributor plate, grow and rise to the bed surface and burst. Thus, gas bubbles motion is the source of particles mixing in such systems resulting in excellent mass and heat transfer, characteristics that are essential for processes involving reaction, drying, mixing, etc. Hence, gas bubbles characteristics including bubble size, rise velocity and frequency are of great importance for a specific application. One factor that affects the gas bubble size and in turn the fluidization quality, is the particle size and distribution. Finer particles tend to be difficult to fluidize while large particles result in poor quality fluidization by formation of very large bubbles known as slugs [114]. Any changes in the bed particles size distribution causes disturbance to the desired fluid bed hydrodynamics by affecting the bubble size and rise velocity and in turn affecting the fluidization behavior. Generation of electrostatic charge of opposite polarity on fluidizing particles results in particle agglomeration which leads to changes in the particles size distribution. In addition, in the case of adhesion of highly charged particles to the fluidization column wall, the particles size distribution within the bed is altered resulting in deviation from the desired bed hydrodynamics.

\subsubsection{Entrainment and particle charging}

One of the main operational challenges of gas-solid fluidized beds is the fine particles carryover. Depending on the nature of the process, the entrained solids could be valuable reactants or products that should be either returned to the bed or recovered, or any other bed material that cannot be sent to downstream unit operations or released to the atmosphere. Therefore, to achieve both technical and economic feasibility of fluidized bed application, a particle recovery system (e.g., cyclone, bag filter, etc.) is typically required downstream of a fluidized bed to capture the entrained particles. However, in order to design gas-solid separators it is necessary to know the entrainment flux (i.e., mass of solids carried out of the fluidized bed per unit cross-sectional area and time). Considerable research has been undertaken to develop empirical correlations to predict the entrainment flux in the past few decades. However, in a recent comprehensive review of the existing entrainment models, Chew et al. concluded that despite of the large number of available correlations, the predictions of these correlations vary widely, where variations of up to a hundredfold are not being unusual [115]. They attributed the discrepancies in these models predictions to the lack of understanding of interparticle effects and namely the cohesive forces.

It is evident that generation of cohesive forces could cause the elutriated particles to form agglomerates or to adhere to the fluidized bed walls, leading to the decline of these particles entrainment rate. However, in many cases the extent of the contribution of the electrostatic forces has been ignored. The influence of electrostatics on entrainment in gas-solid fluidized beds was first observed by researchers where it was found that the elevation of the fluidizing gas relative humidity increased the entrainment flux [104,116,117]. In a later work, while studying the electrostatic effects in fluidization of glass beads and polyethylene particles, Mehrani et al. found that the small particles entrained from the bed were highly charged and carried opposite charges to those of the large bed particles [107]. With their work they pointed out the fact that although numerous entrainment models have been developed by 
many researchers but all ignored the particles charge and the resulting forces in predicting the fines entrainment flux.

Sowinski et al. developed a new charge measurement technique for gas-solid fluidized beds based on the Faraday cup method which enabled the direct measurement of the entrained fines electrostatic charge [97]. Their system consisted of a Faraday cup containing a filter bag located directly at the exit of the fluidization column which measured the charge of entrained fines, while another Faraday cup was placed at the bottom of the fluidization column to measure the charge of the large bed particles. They studied electrostatic charging of polyethylene resin with wide particle size distributions, which in all cases resulted in entrainment. This research team carried out multiple works with this apparatus investigating the effects of various parameters including gas velocity, gas relative humidity and particle size $[48,97,99,118]$. In all cases, they found that the entrained fines had a significant quantity of charge density and of an opposite polarity comparing to the bed particles. Their studies did not include the measurement of entrainment flux.

Maurer et al. also acknowledged the importance of understanding the influence that electrostatic forces can have on fluidizing particles resulting in their entrainment inhibition [119]. They presented a combined modeling and experimental work. They studied the charge density and attrition properties of alumina and dolomite particles in a bubbling fluidized bed. In their model they considered forces including electrostatics, van der Walls, drag, particleparticle collision as well as the gravitational force. Comparison of their experimental results with their model prediction indicated that for the type of particles tested the cohesive van der Walls force was dominating over the electrostatic force in resulting the particles agglomeration and thus the elutriation reduction. However, they concluded that depending on the particles properties electrostatic forces could have a relevant role.

Alsmari et al. carried out experimental work to determine the relation between the entrained particle charge density and their entrainment flux [86]. They developed a particle sampler attached to a Faraday cup that was placed in the freeboard region, at a height of 2 meters above the distributor plate, in a pressurized fluidized bed $(0.15 \mathrm{~m}$ in diameter made of stainless steel). The purpose of the sampler was to measure the charge of the entrained particles. They carried out freely bubbly experiments with various mixtures of large (Geldart group B) and fine (Geldart group A) particles. Particles used included glass beads, alumina and polyethylene. The entrainment rate was measured by collecting the entrained solids through a cyclone at the outlet of the fluidized bed. They concluded that for cases where less electrostatic charge was generated, the entrainment flux was higher due to reduced particle agglomeration and adhesion of particles on the inner column wall. Fotovat et al. [120] continued the work of Alsmari et al. [86] by using the same apparatus and examining the impact of the entrained fines nature (conductive versus non-conductive species) on their charged density measured in the freeboard and their entrainment flux. The coarse particles in their study was glass beads while the fines included glass beads and silver coated glass beads among others. Their results indicated that the entrainment rate of non-conductive fines was noticeably lower. In particular, at very high gas velocities they observed that the entrainment flux of the silver-coated glass beads were approximately six times larger than that of the 
uncoated beads at the same fluidization gas velocity minus the fines terminal velocity. They suggested that the attractive electrostatic forces among the non-conductive particles in the freeboard would have likely promoted particle agglomeration and clustering which had declined their entrainment. The same research team has also initiated works to include the inter-particle electrostatic forces in entrainment flux correlations [121]. They compared their experimental results with one of the commonly employed entrainment flux correlation developed by Choi et al. [122] (equation 1).

$$
\frac{W_{s} d_{p}}{\mu}=A r^{-0.07} \exp \left\{2.90-\frac{25.10}{f_{d}^{2.55}}-5.18 f_{g}^{0.24}\right\}
$$

Where,

$$
\begin{aligned}
& f_{g}=\frac{2}{3} g\left(\rho_{p}-\rho_{g}\right) d_{p} \\
& f_{d}=C_{d} \frac{\rho_{g} U_{g}^{2}}{2}
\end{aligned}
$$

The comparison showed significant differences. They then modified Choi et al. correlation to include the effects of electrostatic forces (equation 4) which had better agreement with the fitted experimental data.

$$
\frac{W_{s} d_{p}}{\mu}=A r^{-2.57} \exp \left\{18.82-1862\left(\frac{\rho_{p}}{\rho_{g}}\right)^{-1.18}-56240 C_{d}{ }^{-3.53}-4.81\left(\frac{q_{m}{ }^{2} \rho_{p} d_{p}{ }^{2}}{\varepsilon_{0} U_{g}{ }^{2}}\right)^{0.27}\right\}
$$

As the authors indicated in order to utilize equation 4, the magnitude of the entrained particles charge density has to be estimated or correlated. Thus, the use of such correlation may be found challenging especially in industrial operations. None the less, this contribution signifies the fact that electrostatic effects should not be neglected in determination of the entrainment rate in gas-solid fluidized beds.

\subsection{Effect of bed hydrodynamics on electrostatic charging}

The operational challenges resulting from bed electrification have continued to be observed in industrial settings and the need for methods of mitigating or eliminating the negative impacts of bed electrification still remains. In order to achieve an ultimate goal of helping the industry with process operability challenges, a better understanding of the underlying mechanisms of charge generation, especially distinguishing the differences between the significance of particle-particle versus particle-wall contacts in such processes is required. Hence, it is not only essential to investigate the electrostatic charge distribution within a fluidized bed, but also the mechanism of fluid bed wall fouling. In this regard, over the past decade some research has focused on better understanding of the relationship between the fluidized bed hydrodynamics and the extend of charge generation and its impacts. 
The net electrostatic charge produced in a fluidized bed is dependent on the degree of contacts within the bed which in turn are influenced by the bed hydrodynamics. There are many operating conditions that influence the hydrodynamics of a fluidized bed, namely fluidizing gas velocity, fluidization operating temperature and pressure, as well as the fluidizing particle size. In recent years, research has been carried out in an attempt to understand the impact of some of these pararmeters on the extent of fluid bed electrification as well as the problem of wall fouling.

\subsubsection{Effect of gas velocity}

Fluidizing gas velocity is one parameter having an impact on the bed hydrodynamics. Increasing the gas velocity will cause the bed to enter various flow regimes including bubbling, slugging and turbulent flow. Industrial fluidized bed reactors are typically operated at bubbling and more so at turbulent flow regimes which promote higher degrees of gas-solid contacts and thus better mass and heat transfer effects. For instance, commercial polyethylene reactors are operated in turbulent flow regime. The particle interactions with themselves and the fluidized bed wall differ between all three flow regimes, hence suggesting having various effects on the electrostatic charge generation. The formation of gas bubbles at the fluidized bed distributor plate and their rise to the bed surface in bubbling flow regime creates significant particle mixing. On the other hand, slugging flow regime consists of large gas bubbles with diameters approaching to that of the fluidization column. This flow regime typically forms in fluidization columns of smaller diameter in lab or pilot-scale systems. The rise of significantly large bubbles in such slugging regime makes the bed of particles to move in sections up and down the column wall, producing less motion in the bed in comparison to bubbling flow regime. Hence, in such state, the particles motion will be mainly limited to the region close to the column wall. Finally, at very high gas velocities turbulent flow regime is achieved where gas bubbles become more frequent and the bed level becomes indistinguishable. In this case, both the interactions between particles and the particles and the column wall are present. Since the triboelectrification is a surface phenomenon, for the case of the fluidization it is important to realize the type of contacts involved (particleparticle or particle-wall) and their governance, in order to effectively find ways to mitigate or eliminate the charge generation.

Majority of research reported in relation to the effect of gas velocity on fluid bed electrification has focused on bubbling flow regime. The earliest work reported in this area dates back to 1962 where Ciborowski and Wlodarski [4] concluded that increasing the gas velocity elevated the bed potential measured by an electrostatic probe. Later others reached a similar conclusion by monitoring the bed electrification through the bed potential, voltage, current from electrostatic probes, and particles charge-to-mass ratio using Faraday cups $[56,57,59,61,84,85,90]$. The conclusion from these works is that in the bubbling flow regime by increasing the gas velocity, the bubble size and rise velocity increases resulting in more particle-particle interaction and consequently the augmentation of the amount of electrostatic charge generation.

Earlier works in relation to slugging flow regime are limited to those by Gajewski, Rojo et al., and Guardiola $[58,60,74]$. These researchers observed that the bed potential reaches a 
maximum followed by a plateau or decline as the gas velocity is increased. In all these works, the bed potential decay was related to the onset of slugging flow regime. Such conclusion is indicative of the fact that particle-particle interactions, being dominated in bubbling flow regime, generated more electrostatic charge than particle-wall interactions which are dominant in slugging flow regime.

Aforementioned works used measurement techniques, mainly electrostatic probes, which were limited to only certain regions of the bed and hence these studies have only focused on the study of the electrostatic charge to the exclusion of wall fouling. Thus, Sowinski et al. further investigated the effects of bubbling versus slugging flow regime by evaluating the particles charge distribution in various regions of the bed and most importantly the variations of the extent of reactor wall fouling [48,97]. With their measurement technique, previously discussed, and using polyethylene resin they varied the gas velocity from $1.5 \mathrm{u}_{\mathrm{mf}}$ to $4.0 \mathrm{u}_{\mathrm{mf}}$ where $2.5 \mathrm{u}_{\mathrm{mf}}$ was the onset of slugging. They measured the height, thickness, as well as the mass and charge of the particle layer fouled on the column wall after one-hour fluidization. The amount of wall coting was found to be larger in bubbling flow regime. Within the bubbling flow regime, they found that the amount of wall layer coating as well as the layer net charge-to-mass ratio increased as the gas velocity increased while at the onset of slugging and beyond the net charge density reached a plateau. The plateau in the results implied that the particles charge was less in the slugging flow regime. Their results further signified the fact that the dominating sources of generation of electrostatic forces (i.e., particle-particle vs. particle-wall interactions) vary from one flow regime to another.

The only work found in relation to the turbulent flow regime is that of the Song et al. [123] who studied the effect of fluidizing gas velocity from bubbling $\left(1.5 \mathrm{u}_{\mathrm{mf}}\right)$ to turbulent $\left(7.5 \mathrm{u}_{\mathrm{mf}}\right)$ flow regime while fluidizing commercial polyethylene resin at high pressures of $2600 \mathrm{kPa}$. The authors found that the extent of wall fouling was approximately five times larger in the turbulent flow in comparison to bubbling flow $\left(1.5 \mathrm{u}_{\mathrm{mf}}\right)$. They also concluded that the charge of particles forming the coating on the column wall increased with the increase in the gas velocity.

\subsubsection{Effect of operating pressure and temperature}

Operating pressure is one of the conditions that influences fluidized bed hydrodynamics mainly by modifying the fluidizing gas density. Since the gas density has significant influence on fluid bed hydrodynamics, the operating pressure then indirectly affects the bed operation including minimum fluidization velocity, the minimum bubbling velocity, and bubble dynamics, and others. Research has shown that elevated pressures cause the mean gas bubble diameter to decrease and the bubble rise velocity to increase for a given excess gas velocity over minimum fluidization velocity [124,125]. In addition, it is found that gas bubble flow to increasingly concentrate towards the centre of the bed at higher pressures [126]. It is known that particle mixing within a fluidized bed is primarily due to the rise of gas bubbles. Therefore, any changes in bubble dynamics will influence the degree of particles collisions within the bed and in turn the degree of fluid bed electrification. 
Up until 2009, all studies found in open literature in relation to fluid beds had been performed at atmospheric pressure and ambient temperature. This is in contrast to the fact that the most significant application of research on electrostatics in gas-solid fluidized beds is related to polyolefin production reactors which operate at high pressures of up to $3000 \mathrm{kPa}$.

Moughrabiah et al. was the first research group to build a pilot-scale pressurized fluidized bed to study electrostatics [84]. Their system consisted of a fluidization column made of stainless steel and $0.15 \mathrm{~m}$ in diameter which housed multiple collision ball probes at various axial and radial locations in the bed. The electrostatic charge generated on the probes during fluidization of glass beads for pressures up to $724 \mathrm{kPa}$ was recorded for $500 \mathrm{~s}$ and used as a measure of the bed electrification. They found that elevating pressure to $724 \mathrm{kPa}$ augmented bed electrification and they associated this finding to an increase in gas bubble rise velocity, frequency and volume fraction based on literature since they did not measure these parameters themselves. In 2010 Liu et al. studied the effect of pressure on fluidization of polyethylene resin using the same apparatus [85]. They used five types of commercial polyethylene resin with various particle size distribution and density. The static bed height was kept similar for all experiments while the operating pressure was varied from 138, to 276, followed by 414 and $621 \mathrm{kPa}$. However, in contrast to their first work [84], the authors concluded that the operating pressure indicated no consistent influence on the electrostatic charging behaviour of polyethylene resin. They attributed such finding to the difficult prediction of the influence of operating pressure on electrostatics due to the complex effects of hydrodynamics.

To satisfy the gap in knowledge in relation to the effect of operating pressure on charge distribution and the charged particles fouling the reactor wall, Salama et al. built a $0.15 \mathrm{~m}$ in diameter fluidized bed able to operate at pressures up to $2600 \mathrm{kPa}$ [127]. They implemented the same electrostatic charge measurement technique developed earlier in the same research team by Sowinski et al. [97]. They compared the bubbling fluidization of a commercial polyethylene resin produced using metallocene catalyst at atmospheric condition and high pressure of $400 \mathrm{kPa}$ for one hour. The authors found that elevating the pressure by only 400 $\mathrm{kPa}$, substantially increased (almost doubled) the amount of reactor wall fouling, although the net charge-to-mass ratio of the fouled particles remained the same. They attributed the similarity in the net specific charge of the particles to the fact that the wall layer had grown at high pressure while consisting of both positively and negatively charged particles, leaving the net the same. In a later work carried out by the same research team, Song at al. presented results of fluidization of a commercial polyethylene resin at atmospheric condition and a more industrially relevant pressure of $2500 \mathrm{kPa}$, while keeping the ratio of the gas velocity to the minimum fluidization velocity constant [101]. Their results indicated that elevating the pressure to $2500 \mathrm{kPa}$ augmented the migration of the charged particles and adhesion on the column wall by a factor of two. They also found that the layer of particles fouled on the column wall included a positively charged outer layer and a negatively charged inner layer (closer to the column wall). They attributed the larger degree of fouling at elevated pressures to the influence of pressure on bed hydrodynamics which resulted in smaller gas bubbles and thus more particles motion and contacts within the bed leading to more particle charging. 
They also concluded that in their case since there existed negligible amount of entrainment, the net specific charge of the bed was mainly due to particles contacting the column wall since the particle-particle contacts would result in a null net charge. They also suggested that the adhesion of the charged particles to the fluidization column wall was due to both the image and electrostatic forces.

In regards to the influence of the fluidization temperature on bed electrification, the research is limited to only one work carried out by Moughrabiah et al [84]. With their aforementioned work related to pressurized fluidization, they also conducted freely bubbling experiment at a pressure of $379 \mathrm{kPa}$ and two temperatures of 20 and $60^{\circ} \mathrm{C}$ while fluidizing a commercial linear low density polyethylene resin. They kept the excess gas velocity and relative humidity constant. Their results showed that the cumulative charge measured by collision ball probes at two axial locations was lower at higher temperature. They attributed this finding to the fact that the bed exhibited smoother fluidization at higher temperature resulting in less electrostatic charge generation.

\subsubsection{Effect of particle size}

The particle size distribution influences the fluidization quality and the dominating forces within the fluidized bed including drag, gravity, and van der Walls. However, depending on the degree of electrostatic charging of the fluidizing particles, electrostatic and image forces could also play a vital role. As Hendrickson noted, the size of the particles can result in electrostatic forces to be comparable to the drag and van der Waals forces [2].

Majority of works including the early works by Boland and Geldart [62], Fasso et al. [95], Gajewski [74] and Guardiola et al. [60] were carried out in mono-sized particle systems where the bed electrification was measured using electrostatic probes. It was concluded by these authors that the increase in the mean particle diameter increased the fluid bed potential. Ali et al. and Zhao et al. conducted experiments with particles having a wide size distribution [37], [39]. They found that the smaller particles carried higher $\mathrm{q} / \mathrm{m}$ value than the larger particles. Both authors also reported the occurrence of bipolar charging where the smaller particles were charged oppositely to those of the larger particles. In majority of the cases they tested, the smaller particles were negatively charged. Fang et al. investigated the bed potential using linear low density polyethylene particles sieved into various size ranges from 80 micron to $1.275 \mathrm{~mm}$ [78]. They kept the gas velocity and the static bed height constant for all particles sizes. Their results showed that increasing the particle size increased the bed potential with a maximum reached at a particle size of $0.394 \mathrm{~mm}$ followed by a decline after. In addition, they observed the bipolar charging phenomenon where bed voltage polarity was found to be reversed near the bed surface. Sowinski et al [100] and Tian and Mehrani [128] also tested the charging behavior of linear low density polyethylene particles of wide size distribution as well as sieved particles. They specifically focused on the effects of particle size on the magnitude of reactor wall fouling due to electrostatics. Their results found that with polyethylene particles as received from a commercial reactor and thus having a very wide particle size distribution, particles of a size of 400 microns and smaller always accumulated on the column wall. They also tested polyethylene particles sieved into narrow size distributions. With these particles they found that while operating the bed at bubbling 
flow regime the size ranges greater than 600 microns did not result in reactor fouling. Tian and Mehrani also evaluated a binary mixture of particle sizes of polyethylene resin [128]. They varied the fraction of small particles (212-300 microns and 300-400 microns) in the mixture with larger particles (600-700 microns) from 0 to $20 \%$. They found that as the fraction of small particles in the mixture increased, the degree of fouling also increased with the coating to consist of mainly the smaller particles. They concluded an important finding that with polyethylene resins commercially produced which have large particle size distribution, the amount of smaller particles plays an important role in the degree of bed electrification and the extent of the particles coating the reactor wall due to electrostatics.

\subsection{Particle mixtures}

Fluidization of binary mixture of two types of particles have been investigated over the years mainly in relation to one type of particle having an antistatic or prostatic properties towards the other. Works within academia date back to 1983 when Wolny and Opalinski [88] found that the addition of additives such as active coal and titanium dioxide decreased the charging of polystyrene particles fluidized in a Perspex column. Similarly, others in academia $[59,104,129]$ evaluated the effects of various types of additives to fluidizing particles such as polyethylene, glass beads, polystyrene. It is important to note that all these works were carried out in either Plexiglas or Perspex columns.

Addition of prostatic agents as a method of controlling sheeting in polyethylene reactors has also been examined in industrial settings. In such cases, the agents introduced either positive charges (e.g., $\mathrm{MgO}, \mathrm{ZnO}, \mathrm{Al} 2 \mathrm{O} 3$, and $\mathrm{CuO}$ ) or negative charges (e.g., $\mathrm{V}_{2} \mathrm{O}_{5}, \mathrm{SiO}_{2}, \mathrm{TiO}_{2}$, and $\mathrm{Fe}_{2} \mathrm{O}_{3}$ ) when added to the fluidized bed of a known charge density [130-132]. In relation to prostatic agents no information is found in literature of their exact effects and the systematic ways of their selection.

In addition to the studies that have focused on the addition of antistatic/prostatic agents, it is essential to realize that in industrial polyethylene fluidized bed reactors more than one type of solid material is present at any given time, namely catalyst and polyethylene particles. There are various types of catalyst that have been used for gas-phase polyethylene reactions, for example, Ziegler-Natta catalysts, chromium based catalysts, and single site catalysts such as metallocene catalysts [133]. The catalyst is typically injected into the reactor in the reaction zone through pneumatic conveying using narrow stainless steel tubes. The overall electrostatic charging within polyethylene reactors could be due to various mechanisms. They include, the catalyst particles being charged during their pneumatic transport to the reactor resulting in image force between the reactor wall and particles upon entering the reactor; and both the polyethylene resin and the catalyst particles being triboelectrically charged through contacts with each other as well as contacts with the reactor wall inside the reactor. Although much work has been carried out in understanding of the charging mechanisms within gassolid fluidized bed polyethylene reactors, very limited attention has been given to understanding of the effect of presence of catalyst on the fluid bed charging. The only work found in open literature is that of Sowisnki and Mehrani [134] who examined the extent of bed electrification and reactor wall fouling for a binary mixture of polyethylene and its 
metallocene catalyst, as well as the catalyst silica support. They carried out their study at atmospheric pressure in bubbling flow regime and injected the powders into the bed by pneumatic transport through a narrow stainless tube. They found that both powders became highly charged through pneumatic conveying, which then resulted in a significant build up of polyethylene particles on the column wall. They concluded that potentially in commercial operations the degree of charging of catalyst through its pneumatic transport into the reactor is an important factor to be considered in finding ways to mitigate the electrostatic effects. The choice of the catalyst support was also pointed out to have a large impact on the degree of bed electrification.

\subsection{Summary and outlook}

Works reported in literature signify the fact that the bed hydrodynamics affects the degree of particle charging in gas-solid fluidized beds. Therefore, in order to understand the bed charging for a specific application it is critical that the experimental work to be carried out under similar operating conditions. The majority of works reported in literature have been conducted at room temperature and pressure in Plexiglas columns using air or nitrogen as the fluidizing gas and operating in the bubbling flow regime. However, for instance for understanding the polyethylene fluidized bed charging, experimental work should be carried out in metallic column in the turbulent flow regime and at elevated pressures and temperatures close to $3000 \mathrm{kPa}$ and $100^{\circ} \mathrm{C}$, respectively. In relation to polyethylene reactor charging, further work is necessary to test the role of additives, namely, various types of catalysts as well as prostatic agents with various surface chemical and physical properties to better understand the underlying mechanisms of their effectiveness in promotion or reduction of reactor wall build-up. Presently the influence of pneumatic conveying of catalyst to the polyethylene reactor as well as the catalyst presence within the reactor is unknown. On the other hand, electrostatic effects on the fluidization behavior, for instance reactor wall fouling and entrainment should not be neglected. These areas of research still require much more attention.

\section{Conclusions}

Controlling, mitigating or eliminating fluidized bed electrification requires a comprehensive understanding of the fluidizing particle triboelectric charging. This paper highlights the progress in this area through a comprehensive review of recent studies aimed at the fundamental understanding of triboelectric charging, development and implementation of electrostatic charge measurement techniques in fluid beds, as well as fluidized bed experiments carried out under various hydrodynamic conditions of the bed.

Key challenges for the future include:

1) improved fundamental understanding of the triboelectric charging process, including identifying the charge species being transferred, developing ways to predict the direction and magnitude of charge transfer, and understanding the role of the mode of contact.

2) development of online monitoring technique that can differentiate contact and induction charging, measure the bipolar distribution of charges on particles, and provide reliable results in large beds under all hydrodynamic conditions. 
3) systematic investigation of beds operating under industrially relevant conditions, including pressures, temperatures and gas velocities, with fluidization columns and particles of similar chemistry to those of commercial reactors. In addition, identification of the dominating mechanisms of contact (i.e., particle-particle versus particle-wall contacts).

4) systematic investigation of the addition of antistatic and prostatic agents. 


\section{References}

[1] B.D. Fulks, S.P. Sawin, C.D. Aikman, J.M. Jenkins, Process for reducing sheeting during polymerization of alpha-olefins, US Patent 4,532,311, 1985. http://www.google.com/patents/US4532311.

[2] G. Hendrickson, Electrostatics and gas phase fluidized bed polymerization reactor wall sheeting, Chem. Eng. Sci. 61 (2006) 1041-1064. doi:10.1016/j.ces.2005.07.029.

[3] W.K. Lewis, E.R. Gilliland, W.C. Bauer, Characteristics of fluidized particles, Ind. Eng. Chem. 41 (1949) 11041117.

[4] J. Ciborowski, A. Wlodarski, On electrostatic effects in fluidized beds, Chem. Eng. Sci. 17 (1962) 23-32.

[5] J. Lowell, A.C. Rose-Innes, Contact electrification, Adv. Phys. 29 (1980) 947-1023. doi:10.1080/00018738000101466.

[6] D.J. Lacks, R. Mohan Sankaran, Contact electrification of insulating materials, J. Phys. D. Appl. Phys. 44 (2011) 453001. doi:10.1088/0022-3727/44/45/453001.

[7] H.A. Mizes, E.M. Conwell, D.P. Salamida, Direct observation of ion transfer in contact charging between a metal and a polymer, Appl. Phys. Lett. 56 (1990) 1597. doi:10.1063/1.103139.

[8] D. Fenzel-Alexander, P. Brock, A. Diaz, Control of Contact Charge in Polymers with Ionomers, Langmuir. 10 (1994) 3323-3327. doi:10.1021/la00021a067.

[9] L.S. McCarty, A. Winkleman, G.M. Whitesides, Electrostatic self-assembly of polystyrene microspheres by using chemically directed contact electrification, Angew. Chemie - Int. Ed. 46 (2007) 206-209. doi:10.1002/anie.200602914.

[10] M.D. Hogue, C.R. Buhler, C.I. Calle, T. Matsuyama, W. Luo, E.E. Groop, Insulatorinsulator contact charging and its relationship to atmospheric pressure, J. Electrostat. 61 (2004) 259-268. doi:10.1016/j.elstat.2004.03.002.

[11] M.D. Hogue, E.R. Mucciolo, C.I. Calle, C.R. Buhler, Two-phase equilibrium model of insulator-insulator contact charging with electrostatic potential, J. Electrostat. 63 (2005) 179-188. doi:10.1016/j.elstat.2004.09.003.

[12] T.R.D. Ducati, L.H. Simoes, F. Galembeck, Charge partitioning at gas-solid interfaces: Humidity causes electricity buildup on metals, Langmuir. 26 (2010) 13763-13766. doi:10.1021/la102494k.

[13] R.F. Gouveia, F. Galembeck, Electrostatic charging of hydrophilic particles due to water adsorption, J. Am. Chem. Soc. 131 (2009) 11381-11386. doi:10.1021/ja900704f.

[14] W.R. Salaneck, Double mass transfer during polymer-polymer contacts, J. Appl. Phys. 47 (1976) 144. doi:10.1063/1.322306.

[15] H.T. Baytekin, A.Z. Patashinski, M. Branicki, B. Baytekin, S. Soh, B.A. Grzybowski, 
The Mosaic of Surface Charge in Contact Electrification, Science (80-. ). 333 (2011) 308 LP-312. http://science.sciencemag.org/content/333/6040/308.abstract.

[16] J. Lowell, A.R. Akande, Contact electrification-why is it variable?, J. Phys. D. Appl. Phys. 21 (1988) 125-137. doi:10.1088/0022-3727/21/1/018.

[17] D.J. Lacks, The unpredictability of electrostatic charging, Angew. Chemie - Int. Ed. 51 (2012) 6822-6823. doi:10.1002/anie.201202896.

[18] W. Jamieson, The electrification of insulating materials, Nature. 83 (1910) 189.

[19] J. Lowell, A.R. Akande, Charge transfer in metal/polymer contacts, J. Phys. D. Appl. Phys. 20 (1987) 565. http://stacks.iop.org/0022-3727/20/i=5/a=002.

[20] A.R. Akande, Annealing effects on the charge transfer in metal/polymer contact, in: Proc. Electrost. Soc. Am. Annu. Meet., Minneapolis, 2008: p. M2. www.electrostatics.org.

[21] M. Sow, D.J. Lacks, R. Mohan Sankaran, Dependence of contact electrification on the magnitude of strain in polymeric materials, J. Appl. Phys. 112 (2012) 84909. doi:10.1063/1.4761967.

[22] M. Sow, R. Widenor, A. Kumar, S.W. Lee, D.J. Lacks, R.M. Sankaran, Strain-induced reversal of charge transfer in contact electrification, Angew. Chemie - Int. Ed. 51 (2012) 2695-2697. doi:10.1002/anie.201107256.

[23] L. Xie, P.F. He, J. Zhou, D.J. Lacks, Correlation of contact deformation with contact electrification of identical materials, J. Phys. D. Appl. Phys. 47 (2014) 215501. doi:10.1088/0022-3727/47/21/215501.

[24] G.S.P. Castle, L.B. Schein, General model of sphere-sphere insulator contact electrification, J. Electrostat. 36 (1995) 165-173.

[25] T. Matsuyama, H. Yamamoto, Charge-relaxation process dominates contact charging of a particle in atmospheric condition: II. The general model, J. Phys. D. Appl. Phys. 30 (1997) 2170. http://stacks.iop.org/0022-3727/30/i=15/a=008.

[26] S. Matsusaka, H. Maruyama, T. Matsuyama, M. Ghadiri, Triboelectric charging of powders: A review, Chem. Eng. Sci. 65 (2010) 5781-5807. doi:10.1016/j.ces.2010.07.005.

[27] D.J. Lacks, R.M. Sankaran, Triboelectric charging in single-component particle systems, Part. Sci. Technol. 34 (2016) 55-62. doi:10.1080/02726351.2015.1043676.

[28] G.D. Freier, The electric field of a large dust devil, J. Geophys. Res. 65 (1960) 35043504. doi:10.1029/JZ065i010p03504.

[29] W.D. Crozier, The electric field of a New Mexico dust devil, J. Geophys. Res. 69 (1964) 5427-5429. doi:10.1029/JZ069i024p05427.

[30] A.I.I. Ette, The effect of the Harmattan dust on atmospheric electric parameters, J. Atmos. Terr. Phys. 33 (1971) 295-300. doi:10.1016/0021-9169(71)90208-X.

[31] C.D. Stow, Dust and sand storm electrification, Weather. 24 (1969) 134-144. doi:10.1002/j.1477-8696.1969.tb03165.x. 
[32] W.M. Farrell, P.H. Smith, G.T. Delory, G.B. Hillard, J.R. Marshall, D. Catling, M. Hecht, D.M. Tratt, N. Renno, M.D. Desch, S.A. Cummer, J.G. Houser, B. Johnson, Electric and magnetic signatures of dust devils from the 2000-2001 MATADOR desert tests, J. Geophys. Res. 109 (2004) E03004. doi:10.1029/2003JE002088.

[33] P. Cartwright, S. Singh, A.G. Bailey, L.J. Rose, Electrostatic charging characteristics of polyethylene powder during pneumatic conveying, IEEE Trans. Ind. Appl. IA-21 (1985) 541-546.

[34] I.I. Inculet, G.S.P. Castle, G. Aartsen, Generation of bipolar electric fields during industrial handling of powders, Chem. Eng. Sci. 61 (2006) 2249-2253. doi:10.1016/j.ces.2005.05.005.

[35] T. Miura, T. Koyaguchi, Y. Tanaka, Measurements of electric charge distribution in volcanic plumes at Sakurajima volcano, Japan, Bull. Volcanol. 64 (2002) 75-93. doi:10.1007/s00445-001-0182-1.

[36] E. Williams, N. Nathou, E. Hicks, C. Pontikis, B. Russell, M. Miller, M.J. Bartholomew, The electrification of dust-lofting gust fronts ('haboobs') in the Sahel, Atmos. Res. 91 (2009) 292-298. doi:10.1016/j.atmosres.2008.05.017.

[37] F. Sharmene Ali, M. Adnan Ali, R. Ayesha Ali, I.I. Inculet, Minority charge separation in falling particles with bipolar charge, J. Electrostat. 45 (1998) 139-155. doi:10.1016/S0304-3886(98)00044-8.

[38] H. Zhao, G.S.P. Castle, I.I. Inculet, The measurement of bipolar charge in polydisperse powders using a vertical array of Faraday pail sensors, J. Electrostat. 55 (2002) 261278. doi:10.1016/S0304-3886(01)00209-1.

[39] H. Zhao, G.S.P. Castle, I.I. Inculet, A.G. Bailey, Bipolar charging of poly-disperse polymer powders in fluidized beds, IEEE Trans. Ind. Appl. 39 (2003) 612-618. doi:10.1109/TIA.2003.810663.

[40] S. Trigwell, N. Grable, C.U. Yurteri, R. Sharma, M.K. Mazumder, Effects of surface properties on the tribocharging characteristics of polymer powder as applied to industrial processes, IEEE Trans. Ind. Appl. 39 (2003) 79-86. doi:10.1109/TIA.2002.807228.

[41] K.M. Forward, D.J. Lacks, R.M. Sankaran, Charge segregation depends on particle size in triboelectrically charged granular materials, Phys. Rev. Lett. 102 (2009) 28001. doi:10.1103/PhysRevLett.102.028001.

[42] K.M. Forward, D.J. Lacks, R.M. Sankaran, Triboelectric charging of granular insulator mixtures due solely to particle - Particle interactions, Ind. Eng. Chem. Res. 48 (2009) 2309-2314. doi:10.1021/ie8004786.

[43] K.M. Forward, D.J. Lacks, R.M. Sankaran, Methodology for studying particle-particle triboelectrification in granular materials, J. Electrostat. 67 (2009) 178-183. doi:10.1016/j.elstat.2008.12.002.

[44] F. Salama, P. Mehrani, Electrostatic charge generation and wall fouling in a highpressure gas-solid fluidized bed: Implementation and preliminary testing of a measurement technique, University of Ottawa, 2013. 
[45] M.A. Bilici, J.R. Toth, R.M. Sankaran, D.J. Lacks, Particle size effects in particleparticle triboelectric charging studied with an integrated fluidized bed and electrostatic separator system., Rev. Sci. Instrum. 85 (2014) 103903. doi:10.1063/1.4897182.

[46] S.R. Waitukaitis, V. Lee, J.M. Pierson, S.L. Forman, H.M. Jaeger, Size-dependent same-material tribocharging in insulating grains, Phys. Rev. Lett. 112 (2014) 1-5. doi:10.1103/PhysRevLett.112.218001.

[47] V. Lee, S.R. Waitukaitis, M.Z. Miskin, H.M. Jaeger, Direct observation of particle interactions and clustering in charged granular streams, Nat. Phys. 11 (2015) 733-737. doi:10.1038/nphys3396.

[48] A. Sowinski, L. Miller, P. Mehrani, Investigation of electrostatic charge distribution in gas-solid fluidized beds, Chem. Eng. Sci. 65 (2010) 2771-2781. doi:10.1016/j.ces.2010.01.008.

[49] X.J. Zheng, N. Huang, Y.-H. Zhou, Laboratory measurement of electrification of wind-blown sands and simulation of its effect on sand saltation movement, J. Geophys. Res. Atmos. 108 (2003) 4322. doi:10.1029/2006JD008254.

[50] C.E. Krauss, M. Horányi, S. Robertson, Experimental evidence for electrostatic discharging of dust near the surface of Mars, New J. Phys. 5 (2003) 70.1-70.9. doi:10.1088/1367-2630/5/1/370.

[51] D.J. Lacks, A. Levandovsky, Effect of particle size distribution on the polarity of triboelectric charging in granular insulator systems, J. Electrostat. 65 (2007) 107-112. doi:10.1016/j.elstat.2006.07.010.

[52] D.J. Lacks, N. Duff, S.K. Kumar, Nonequilibrium Accumulation of Surface Species and Triboelectric Charging in Single Component Particulate Systems, Phys. Rev. Lett. 100 (2008) 188305. doi:10.1103/PhysRevLett.100.188305.

[53] G.S.P. Castle, Contact charging between particles; Some current understanding, in: Proc. 2008 Annu. Meet. Electrost. Soc. Am., 2008. www.electrostatics.org.

[54] L. Xie, G. Li, N. Bao, J. Zhou, Contact electrification by collision of homogenous particles, J. Appl. Phys. 113 (2013) 184908. doi:10.1063/1.4804331.

[55] T. Pähtz, H.J. Herrmann, T. Shinbrot, Why do Particle Clouds Generate Electric Charges?, Nat. Phys. 6 (2010) 364-368. doi:10.1038/nphys1631.

[56] V.N. Kisel'nikov, V. V Vyalkov, V.M. Filatov, On the problem of electrostatic phenomena in a fluidized bed, Int. Chem. Eng. 7 (1967) 428-431.

[57] M. Bafrnec, J. Beňa, Quantitative data on the lowering of electrostatic charge in a fluidized bed, Chem. Eng. Sci. 27 (1972) 1177-1181. doi:10.1016/00092509(72)80030-7.

[58] V. Rojo, J. Guardiola, A. Vian, A capacitor model to interpret the electric behaviour of fluidized beds. Influence of apparatus geometry, Chem. Eng. Sci. 41 (1986) 21712181. doi:10.1016/0009-2509(86)87133-0.

[59] J. Guardiola, G. Ramos, A. Romero, Electrostatic behaviour in binary dielectric/conductor fluidized beds, Powder Technol. 73 (1992) 11-19. 
doi:10.1016/0032-5910(92)87002-R.

[60] J. Guardiola, V. Rojo, G. Ramos, Influence of particle size, fluidization velocity and relative humidity on fluidized bed electrostatics, J. Electrostat. 37 (1996) 1-20. doi:10.1016/0304-3886(96)00002-2.

[61] M. Fujino, S. Ogata, H. Shinohara, The electric potential distribution profile in a naturally charged fluidized bed and its effects, Int. Chem. Eng. 25 (1985) 149-159.

[62] D. Boland, D. Geldart, Electrostatic charging in gas fluidised beds, Powder Technol. 5 (1972) 289-297. doi:10.1016/0032-5910(72)80033-0.

[63] A.A. Park, H.T. Bi, J.R. Grace, A. Chen, Modeling charge transfer and induction in gas - solid fluidized beds, J. Electrostat. 55 (2002) 135-158.

[64] L. Yao, H.T. Bi, A.H. Park, Characterization of electrostatic charges in freely bubbling fluidized beds with dielectric particles, J. Electrostat. 56 (2002) 183-197. doi:10.1016/S0304-3886(02)00062-1.

[65] A. Chen, H. Bi, J.R. Grace, Effects of charge distribution around bubbles on charge induction and transfer to a ball probe in gas-solid fluidized beds, J. Electrostat. 58 (2003) 91-115. doi:10.1016/S0304-3886(02)00201-2.

[66] A.H. Chen, H.T. Bi, J.R. Grace, Measurement of particle charge-to-mass ratios in a gas-solids fluidized bed by a collision probe, Powder Technol. 135-136 (2003) 181191. doi:10.1016/j.powtec.2003.08.014.

[67] C. Zhu, S.L. Soo, A modified theory for electrostatic probe measurements of particle mass flows in dense gas-solid suspensions, J. Appl. Phys. 72 (1992) 2060. doi:10.1063/1.351636.

[68] A. Chen, H. Bi, J.R. Grace, Effects of probe numbers and arrangement on the measurement of charge distributions around a rising bubble in a two-dimensional fluidized bed, Chem. Eng. Sci. 61 (2006) 6499-6510. doi:10.1016/j.ces.2006.05.047.

[69] A. Chen, H.T. Bi, J.R. Grace, Charge distribution around a rising bubble in a twodimensional fluidized bed by signal reconstruction, Powder Technol. 177 (2007) 113124. doi:10.1016/j.powtec.2007.02.036.

[70] M. Murtomaa, E. Räsänen, J. Rantanen, A. Bailey, E. Laine, J.P. Mannermaa, J. Yliruusi, Electrostatic measurements on a miniaturized fluidized bed, J. Electrostat. 57 (2003) 91-106.

[71] J. Peltonen, M. Murtomaa, J. Salonen, A coaxial induction probe for measuring the charge, size and distance of a passing object, J. Electrostat. 77 (2015) 94-100.

[72] M. Murtomaa, J. Salonen, Simultaneous measurement of particle charge, distance and size using coaxial induction probe, in: J. Phys. Conf. Ser., 2015: p. 12038. http://iopscience.iop.org/article/10.1088/1742-6596/646/1/012038/meta.

[73] J. Peltonen, M. Murtomaa, A. Saikkonen, J. Salonen, A coaxial probe with a vertically split outer sensor for charge and dimensional measurement of a passing object, Sensors Actuators, A Phys. 244 (2016) 44-49. 
[74] A. Gajewski, Investigation of the electrification of polypropylene particles during the fluidization process, J. Electrostat. 17 (1985) 289-298. doi:10.1016/03043886(85)90029-4.

[75] Q. Zhang, K. Dong, Y. Zhou, Z. Huang, Z. Liao, J. Wang, Y. Yang, F. Wang, A comparative study of electrostatic current and pressure signals in a MSFC gas-solid fluidized bed, Powder Technol. 287 (2016) 292-300.

doi:10.1016/j.powtec.2015.10.005.

[76] P. Tiyapiboonchaiya, D. Gidaspow, S. Damronglerd, Hydrodynamics of electrostatic charge in polypropylene fluidized beds, Ind. Eng. Chem. Res. 51 (2012) 8661-8668. http://www.scopus.com/inward/record.url?eid=2-s2.084863227433\&partnerID=40\&md5=f6ac3904062c37059f9da2d40911e1b8.

[77] J. McMillan, M. Dawe, C. Briens, F. Berruti, Measurement technique for the on-line detection of fines in a fluidized bed, Meas. J. Int. Meas. Confed. 44 (2011) 1436-1440. doi:10.1016/j.measurement.2011.05.006.

[78] W. Fang, W. Jingdai, Y. Yongrong, Distribution of Electrostatic Potential in a Gas Solid Fluidized Bed and Measurement of Bed Level, Ind. Eng. Chem. Res. 47 (2008) 9517-9526.

[79] J. Wang, Y. Xu, W. Li, Y. Yang, F. Wang, Electrostatic potentials in gas-solid fluidized beds influenced by the injection of charge inducing agents, J. Electrostat. 67 (2009) 815-826. doi:10.1016/j.elstat.2009.06.005.

[80] Y. Zhou, C. Ren, J. Wang, Y. Yang, K. Dong, Effect of hydrodynamic behavior on electrostatic potential distribution in gas-solid fluidized bed, Powder Technol. 235 (2013) 9-17. doi:10.1016/j.powtec.2012.09.025.

[81] F. Portoghese, F. Berruti, C. Briens, Use of triboelectric probes for on-line monitoring of liquid concentration in wet gas-solid fluidized beds, Chem. Eng. Sci. 60 (2005) 6043-6048. doi:10.1016/j.ces.2005.03.042.

[82] F. Portoghese, F. Berruti, C. Briens, Continuous on-line measurement of solid moisture content during fluidized bed drying using triboelectric probes, Powder Technol. 181 (2008) 169-177. doi:10.1016/j.powtec.2007.01.003.

[83] W. Brennan, M. Jacobson, G. Book, C. Briens, L. Briens, Development of a tribolelectric procedure for the measurement of mixing and drying in a vibrated fluidized bed, Powder Technol. 181 (2008) 178-185. doi:10.1016/j.powtec.2006.12.002.

[84] W.O. Moughrabiah, J.R. Grace, X.T. Bi, Effects of pressure, temperature, and gas velocity on electrostatics in gas - solid fluidized beds, Ind. Eng. Chem. Res. 48 (2009) 320-325. doi:10.1021/ie800556y.

[85] Z. Liu, X.T. Bi, J.R. Grace, Electrostatic charging behaviour of dielectric particles in a pressurized gas-solid fluidized bed, J. Electrostat. 68 (2010) 321-327. doi:10.1016/j.elstat.2010.03.006.

[86] T.A. Alsmari, J.R. Grace, X.T. Bi, Effects of particle properties on entrainment and electrostatics in gas-solid fluidized beds, Powder Technol. 290 (2016) 2-10. 
doi:10.1016/j.powtec.2015.06.074.

[87] M.E. Muhle, R.O. Hagerty, J.F. Szul, M.G. Goode, L.G. Britton, Static measurement and detection in a gas phase polyethylene reactor, WO2004/060940 A1, 2004.

[88] A. Wolny, I. Opaliǹski, Electric charge neutralization by addition of fines to a fluidized bed composed of coarse dielectric particles, J. Electrostat. 14 (1983) 279289. doi:10.1016/0304-3886(83)90026-8.

[89] F. Sharmene Ali, I.I. Inculet, A. Tedoldi, Charging of polymer powder inside a metallic fluidized bed, J. Electrostat. 45 (1999) 199-211. doi:10.1016/S03043886(98)00050-3.

[90] J. Revel, C. Gatumel, J.A. Dodds, J. Taillet, Generation of static electricity during fluidisation of polyethylene and its elimination by air ionisation, Powder Technol. 135-136 (2003) 192-200. doi:10.1016/j.powtec.2003.08.015.

[91] L. Zhang, J. Hou, X.T. Bi, J.R. Grace, T. Janke, C. Arato, Fluidization characteristics and charging behavior of fly ash in a vibro-fluidized bed, Powder Technol. 215-216 (2012) 235-241. doi:10.1016/j.powtec.2011.10.005.

[92] G. Tardos, R. Pfeffer, A method to measure electrostatic charge on a granule in a fluidized bed, Chem. Eng. Commun. 4 (1980) 665-671. doi:10.1080/00986448008935938.

[93] F. Jalalinejad, Electro-hydrodynamics of gas-solid fluidized bed, University of British Columbia, 2013.

[94] F. Jalalinejad, X.T. Bi, J.R. Grace, Comparison of theory with experiment for single bubbles in charged fluidized particles, Powder Technol. 290 (2016) 27-32. doi:10.1016/j.powtec.2015.12.014.

[95] L. Fasso, B.T. Chao, S.L. Soo, Measurement of electrostatic charges and concentration of particles in the freeboard of a fluidized bed, Powder Technol. 33 (1982) 211-221. doi:10.1016/0032-5910(82)85060-2.

[96] T.A. Alsmari, Effect of operation conditions and particle properties on electrostatics and entrainment in gas-solid fluidized beds, University of British Columbia, Vancouver, Canada, 2014.

[97] A. Sowinski, F. Salama, P. Mehrani, New technique for electrostatic charge measurement in gas-solid fluidized beds, J. Electrostat. 67 (2009) 568-573. doi:10.1016/j.elstat.2008.11.005.

[98] M. Murtomaa, J. Peltonen, J. Salonen, One-step measurements of powder resistivity as a function of relative humidity and its effect on charging, J. Electrostat. 76 (2015) 7882. doi:10.1016/j.elstat.2015.05.016.

[99] A. Giffin, P. Mehrani, Comparison of influence of fluidization time on electrostatic charge build-up in the bubbling vs. slugging flow regimes in gas-solid fluidized beds, J. Electrostat. 68 (2010) 492-502. doi:10.1016/j.elstat.2010.06.013.

[100] A. Sowinski, A. Mayne, P. Mehrani, Effect of fluidizing particle size on electrostatic charge generation and reactor wall fouling in gas-solid fluidized beds, Chem. Eng. Sci. 
71 (2012) 552-563. doi:10.1016/j.ces.2011.11.031.

[101] D. Song, F. Salama, J. Matta, P. Mehrani, Implementation of Faraday cup electrostatic charge measurement technique in high-pressure gas-solid fluidized beds at pilot-scale, Powder Technol. 290 (2016) 21-26. doi:10.1016/j.powtec.2015.05.049.

[102] F. Salama, A. Sowinski, K. Atieh, P. Mehrani, Investigation of electrostatic charge distribution within the reactor wall fouling and bulk regions of a gas-solid fluidized bed, J. Electrostat. 71 (2013) 21-27. doi:10.1016/j.elstat.2012.11.002.

[103] V. Albrecht, A. Janke, E. Németh, S. Spange, G. Schubert, F. Simon, Some aspects of the polymers' electrostatic charging effects, J. Electrostat. 67 (2009) 7-11.

doi:10.1016/j.elstat.2008.10.002.

[104] A. Wolny, W. Kaźmierczak, Triboelectrification in fluidized bed of polystyrene, Chem. Eng. Sci. 44 (1989) 2607-2610. doi:10.1016/0009-2509(89)85204-2.

[105] S. Watano, T. Suzuki, T. Taira, K. Miyanami, Continuous monitoring and mechanism of electrostatic charge of powder in fluidized bed process, Chem. Pharm. Bull. 46 (1998) 1438-1443.

[106] P. Mehrani, H.T. Bi, J.R. Grace, Electrostatic charge generation in gas-solid fluidized beds, J. Electrostat. 63 (2005) 165-173. doi:10.1016/j.elstat.2004.10.003.

[107] P. Mehrani, H.T. Bi, J.R. Grace, Electrostatic behavior of different fines added to a Faraday cup fluidized bed, J. Electrostat. 65 (2007) 1-10.

doi:10.1016/j.elstat.2006.05.002.

[108] C. He, X.T. Bi, J.R. Grace, Contact electrification of a novel dual-material probe with charged particulate flow, Powder Technol. 253 (2014) 1-9. doi:10.1016/j.powtec.2013.10.042.

[109] H. Watanabe, A. Samimi, Y.L. Ding, M. Ghadiri, T. Matsuyama, K.G. Pitt, Measurement of charge transfer due to single particle impact, Part. Part. Syst. Charact. 23 (2006) 133-137. doi:10.1002/ppsc.200601021.

[110] C. He, X.T. Bi, J.R. Grace, A novel dual-material probe for in situ measurement of particle charge densities in gas-solid fluidized beds, Particuology. 21 (2015) 20-31. doi:10.1016/j.partic.2014.11.001.

[111] C. He, X.T. Bi, J.R. Grace, Simultaneous measurements of particle charge density and bubble properties in gas-solid fluidized beds by dual-tip electrostatic probes, Chem. Eng. Sci. 123 (2015) 11-21. doi:10.1016/j.ces.2014.10.023.

[112] C. He, X.T. Bi, J.R. Grace, Decoupling electrostatic signals from gas-solid bubbling fluidized beds, Powder Technol. 290 (2016) 11-20. doi:10.1016/j.powtec.2015.06.022.

[113] J.R. Grace, D. Harrison, The influence of bubble shape on the rising velocities of large bubbles, Chem. Eng. Sci. 22 (1967) 1337-1347. doi:10.1016/0009-2509(67)80024-1.

[114] D. Kunii, O. Levenspiel, Fluidization Engineering, Buttenworth-Heinemann, Newton, USA, 1991.

[115] J.W. Chew, A. Cahyadi, C.M. Hrenya, R. Karri, R.A. Cocco, Review of entrainment 
correlations in gas-solid fluidization, Chem. Eng. J. 260 (2015) 152-171.

doi:10.1016/j.cej.2014.08.086.

[116] T. Baron, C.L. Briens, M.A. Bergougnou, J.D. Hazlett, Electrostatic effects on entrainment from a fluidized bed, Powder Technol. 57 (1987) 55-67.

doi:10.1016/0032-5910(87)80125-0.

[117] C.L. Briens, T. Baron, M.A. Bergougnou, I.I. Inculet, J.D. Hazlett, Size distribution of particles entrained from fluidized beds: electrostatic effects, Powder Technol. 70 (1992) 57-62.

[118] A. Giffin, P. Mehrani, Effect of gas relative humidity on reactor wall fouling generated due to bed electrification in gas-solid fluidized beds, Powder Technol. 235 (2013) 368-375. doi:10.1016/j.powtec.2012.10.037.

[119] S. Maurer, S.R. Durán, M. Künstle, S.M.A. Biollaz, Influence of interparticle forces on attrition and elutriation in bubbling fluidized beds, Powder Technol. 291 (2016) 473486. doi:10.1016/j.powtec.2015.12.026.

[120] F. Fotovat, J.R. Grace, X.T. Bi, Particle entrainment from gas-solid fluidized beds: conductive vs. dielectric fines, AIChE J. in Press (2016).

[121] F. Fotovat, T.A. Alsmari, J.R. Grace, X.T. Bi, The relationship between fluidized bed electrostatics and entrainment, Powder Technol. In Press (2016).

[122] J.-H. Choi, I.-Y. Chang, D.-W. Shun, C.-K. Yi, J.-E. Son, S.-D. Kim, Correlation on the Particle Entrainment Rate in Gas Fluidized Beds, Ind. Eng. Chem. Res. 38 (1999) 2491-2496. doi:10.1021/ie980707i.

[123] D. Song, P. Mehrani, Comparison of Electrostatic Charge Generation in Gas-solid Fluidized Beds in Turbulent versus Pre-Turbulent Flow Regime, Powder Technol. Submitted (2017).

[124] D. Fiorention, D. Newton, Application of X-ray imaging to fluidized bed scale up, in: L.S. Fan, T.M. Knowlton (Eds.), Fluid. IX, Engineering Foundation, New York, 1998: p. 589.

[125] A.C. Hoffmann, J.G. Yates, Experimental Observations of Fluidized Beds At Elevated Pressures, Chem. Eng. Commun. 41 (1986) 133-149. doi:10.1080/00986448608911716.

[126] P.A. Olowson, A.E. Almstedt, Influence of pressure and fluidization velocity on the bubble behaviour and gas flow distribution in a fluidized bed, Chem. Eng. Sci. 45 (1990) 1733-1741.

[127] F. Salama, D. Song, P. Mehrani, Characterizing Electrostatic Charges in High-Pressure Gas- Solid Fluidized Beds : Experimental Design and Preliminary Results, in: Proc. 14th Int. Conf. Fluid., 2013.

[128] Y. Tian, P. Mehrani, Effect of particle size in fluidization of polyethylene particle mixtures on the extent of bed electrification and wall coating, J. Electrostat. 76 (2015) 138-144. doi:10.1016/j.elstat.2015.05.020.

[129] W.O. Moughrabiah, J.R. Grace, X.T. Bi, Electrostatics in gas-solid fluidized beds for 
different particle properties, Chem. Eng. Sci. 75 (2012) 198-208. doi:10.1016/j.ces.2012.02.041.

[130] G.-H. Song, A.S. Rhee, G.R. Lowder, Method for reducing sheeting and static charges during polymerization of ethylene polymers, US Patent 5,391,657, 1995.

[131] R.O. Hagerty, M.E. Muhle, A.K. Agapiou, C.-T. Kuo, M.G. Goode, F.D. Hussein, R.B. Pannell, J.F. Szul, Method for controlling sheeting in gas phase reactors, US Patent 0148742 A1, 2005.

[132] R.O. Hagerty, M.E. Muhle, A.K. Agapiou, C.-T. Kuo, M.G. Goode, F.D. Hussein, R.B. Pannell, J.F. Szul, Method for controlling sheeting in gas phase reactors, US Patent 7985811 B2, 2011.

[133] D.B. Malpass, Introduction to industrial polyethylene: Properties, catalysts, processes, Scrivener-Wiley, Salem, MA, 2010.

[134] A. Sowinski, P. Mehrani, Impact of addition of a catalyst or its support on reactor wall coating due to electrostatic charging during fluidization of polyethylene, Ind. Eng. Chem. Res. 54 (2015) 3981-3988. doi:10.1021/ie5047686. 
Nomenclature

\begin{tabular}{|l|l|}
\hline Symbol & Definition (units) \\
\hline$A r$ & Archimedes number \\
\hline$C_{d}$ & Drag coefficient $(-)$ \\
\hline$d_{\mathrm{p}}$ & Particle diameter $(\mathrm{m})$ \\
\hline$f_{\mathrm{d}}$ & Drag force per projected area of particle $\left(\mathrm{kg} / \mathrm{m} . \mathrm{s}^{2}\right)$ \\
\hline$f_{\mathrm{g}}$ & Gravity force per projected area of particle $\left(\mathrm{kg} / \mathrm{m}^{2} \mathrm{~s}^{2}\right)$ \\
\hline$g$ & Gravitational constant $\left(\mathrm{m} / \mathrm{s}^{2}\right)$ \\
\hline$q_{m}$ & Mass charge density $(\mathrm{C} / \mathrm{kg})$ \\
\hline$U_{\mathrm{g}}$ & Superficial gas velocity $(\mathrm{m} / \mathrm{s})$ \\
\hline$U_{\mathrm{mf}}$ & Minimum fluidization velocity of particles $(\mathrm{m} / \mathrm{s})$ \\
\hline$W_{\mathrm{s}}$ & Entrainment flux of solid particles $\left(\mathrm{kg} / \mathrm{m}^{2} . \mathrm{s}\right)$ \\
\hline$\varepsilon_{0}$ & Vacuum permittivity $(\mathrm{F} / \mathrm{m})$ \\
\hline$\mu$ & Dynamic viscosity of gas $(\mathrm{kg} / \mathrm{m} . \mathrm{s})$ \\
\hline$\rho_{\mathrm{g}}$ & Gas density $\left(\mathrm{kg} / \mathrm{m}^{3}\right)$ \\
\hline$\rho_{\mathrm{p}}$ & Particle density $\left(\mathrm{kg} / \mathrm{m}^{3}\right)$ \\
\hline
\end{tabular}

